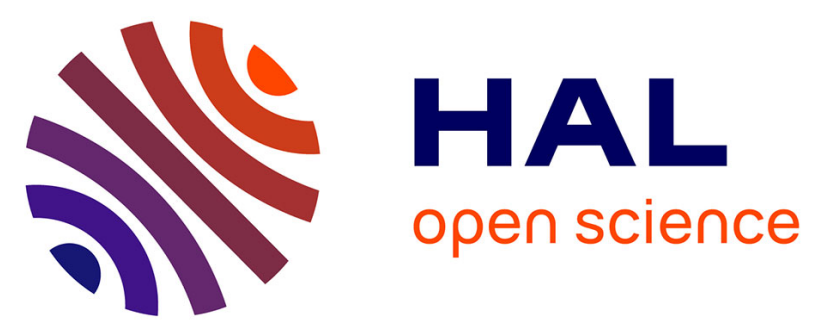

\title{
Effects of anion size on the electrochemical behavior of H2SO4-structured poly(o-toluidine) films. An ac-electrogravimetry study in acid solutions
}

J. Agrisuelas, Claude Gabrielli, J.J. Garcia-Jareño, Hubert Perrot, F. Vicente

\section{- To cite this version:}

J. Agrisuelas, Claude Gabrielli, J.J. Garcia-Jareño, Hubert Perrot, F. Vicente. Effects of anion size on the electrochemical behavior of $\mathrm{H} 2 \mathrm{SO} 4$-structured poly(o-toluidine) films. An ac-electrogravimetry study in acid solutions. Electrochimica Acta, 2014, 132, pp.561-673. 10.1016/j.electacta.2014.04.047 . hal-01023055

\section{HAL Id: hal-01023055 \\ https://hal.sorbonne-universite.fr/hal-01023055}

Submitted on 18 Jul 2014

HAL is a multi-disciplinary open access archive for the deposit and dissemination of scientific research documents, whether they are published or not. The documents may come from teaching and research institutions in France or abroad, or from public or private research centers.
L'archive ouverte pluridisciplinaire HAL, est destinée au dépôt et à la diffusion de documents scientifiques de niveau recherche, publiés ou non, émanant des établissements d'enseignement et de recherche français ou étrangers, des laboratoires publics ou privés. 
Effects of anion size on the electrochemical behavior of $\mathrm{H}_{2} \mathrm{SO}_{4}$-structured poly(otoluidine) films. An ac-electrogravimetry study in acid solutions.

\footnotetext{
J. Agrisuelas* ${ }^{\dagger \dagger}$, C. Gabrielli ${ }^{\dagger, \star}$, J. J. García-Jareño ${ }^{\S}$, H. Perrot ${ }^{\dagger, \star}$ and F. Vicente ${ }^{\S}$

$\dagger$ Laboratoire Interfaces et Systèmes Électrochimiques (LISE), UPR $15 \mathrm{du}$ CNRS, Centre National de la Recherche Scientifique (CNRS), 4 place Jussieu, 75005 Paris, France

$\$$ LISE, Université Pierre et Marie Curie-Paris 6 (UPMC), 4 place Jussieu, 75005 Paris, France

$\S$ Departament de Química Física, Universitat de València. C/Dr. Moliner, 50, 46100, Burjassot, València, Spain
}

*E-mail: jeronimo.agrisuelas@uv.es 


\begin{abstract}
$a c$-Electrogravimetry has allowed an easy separation of kinetic information to be evaluated for all the transferred species in three different $\mathrm{H}_{2} \mathrm{SO}_{4}$-structured poly(otoluidine) or POT films, POT- $\mathrm{NO}_{3}^{-}, \mathrm{POT}_{-} \mathrm{ClO}_{4}^{-}$and $\mathrm{POT}-\mathrm{Cl}^{-}$films when they are polarized between the pernigraniline (oxidized) and leucoemeraldine (reduced) forms. It is clear that larger anions slow down the electrochemical transitions of POT films, but the effects of anion transfer on hydrated protons and free solvent transfers are affected. For the same polymeric structure of a POT film, the kinetics of all specie transfers have been evaluated considering the size of species, geometric molecular structure, the interactions with the polymer structure of POT, the hydrophobicity of species transferred, the polymeric rearrangements and the oxidation state of the film. When the polymeric structure is not adapted to the anion in solution, the transfer of non-charged molecules has a mixed kinetic control depending on anion transfer and mechanical contractions/expansions of film. By taking into account all these considerations, the versatility of one type of sensor device could be improved and extended to different analytical situations.
\end{abstract}

Keywords: Intrinsically conducting polymer, Poly(o-toluidine), Electrochemical quartz crystal microbalance, Electrochemical impedance spectroscopy, $a c$-Electrogravimetry. 


\section{Introduction}

Intrinsically conducting polymers (ICPs) have time stability, good processability and low relative cost [1-7]. During the last 20 years, ICPs are used in different applications like electrochromic devices [8,9], photogalvanic cells [10], artificial muscles [11,12], light-emitting electrochemical cells [13,14], biosensors [15-19], biofuel cells-based devices [20,21]. The properties of ICPs are directly related to the oxidation state of the electroactive sites, which can be modulated by electrochemical oxidation/reduction processes. A classical model to interpret electron conduction through these redox and conducting films supposes that during these processes, electrical conduction through the film needs to pass some potential barriers. First, there is the electron transfer at the electrode|film interface. The second potential barrier corresponds to the charge transport through the film, which is neglected when the deposited polymers are thin enough. At last, there is the exchange of charged species (cations and/or anions) at the film|solution interface needed for the electrical charge balance. In addition, free solvent transfer between the solution and the polymer often occurs in order to satisfy activity constraints. In thin films of ICPs, the apparent kinetics are controlled by the slowest of these processes; in fact, the species transfer in the film|solution interface is often the rate-determining step.

A great amount of attention has been paid to understand the effect of the size and mobility of the incorporated anions in ICPs [22-33]. In particular, a significant influence of the dopant type on the properties of polyaniline and its derivatives has been reported. Generally, the most of studies of these films are focused on the transfer of charge carriers because they are directly related to the electrical response. Larger anions decrease the conductivity of electrogenerated films [22,33-35]. Likewise, other responses can be marked by the anion identity, which lead to compact or open film structures during the polymerization [26], increase the grow rates of polymerization [28], slow the color response [29], increase the stiffness [24] and increase the mean $\pi$ conjugated length [23] of films.

In spite of this, aspects such as the influence of other participating species, the structure of films, or the overlapping with other electrochemical reactions are often not taken into account and, finally, global responses are discussed because only few analytical techniques can provide information of the dynamic electrochemical events in a more detailed way. In-situ coupled techniques can extend the aspects of anion size on 
electrochemistry of this kind of polymers. As an example, the electrochemical quartz crystal microbalance (EQCM) with probe beam deflection can show the influence of anion on other mobile species [36-38]. Among all in-situ coupled techniques, acelectrogravimetry has revealed, during last few years, an easy and fast discrimination between cation and anion transfers involved in the charge compensation process together with a noticeable kinetic information when electrochemical and mass impedance spectroscopy are discussed together [39-42].

In a previous work [43], the ionic and free water transfers were studied in three different films of polyaniline generated in $\mathrm{HCl}, \mathrm{HNO}_{3}$ and $\mathrm{HClO}_{4}$ aqueous solutions. Later, $a c$-electrogravimetry measurements were carried out in the same monomer-free acid solution. Results proved that the anion size clearly affects kinetics of both the anion transfer and the free water transfer. However, the anions in the solution of electrogeneration largely determine the final structure of the generated polymer (compact or open structure) [28]. A priori, the molecular structure of the film should define the amount of void space occupied by free water molecules and the size of the ionic channels. The inner aqueous matrix of films generates a lower viscous medium where anions can move freely according to the degree of hydration, as well as, it facilitates the molecular chain motion [24]. Both features can change during the electrochemical transitions and, therefore, affect the kinetic responses of mobile species [44,45].

Among all conductive polyaniline derivatives, poly(o-toluidine) (POT) is one of the most studied [37,38,46-52]. This film is chosen in this work because it shows electron localization greater than that of polyaniline [53,54]. This fact favors the formation of time-stable intermediated structures, polarons and bipolarons, allowing the kinetic information of both structures to be discerned and extended to other polyaniline derivatives. Recently, a general kinetic scheme of POT in $0.5 \mathrm{M} \mathrm{H}_{2} \mathrm{SO}_{4}$ solution with three different redox reaction steps was proposed between the oxidized form (pernigraniline salt, PN) and the reduced form (leucoemeraldine salt, LE) [45]. The polaron form (P) and the bipolaron form (BP) of this film were considered as single entities with measurable and individual electrochemical kinetics. The reaction schema proposed was:

$$
\mathrm{LE}+n_{1} \mathrm{HSO}_{4}^{-} \stackrel{k_{1}^{\prime}}{\longleftarrow} \mathrm{P}+n_{1} \mathrm{e}^{-}+x_{1} \mathrm{H}_{2} \mathrm{O}
$$




$$
\begin{gathered}
\mathrm{P}+n_{2} \mathrm{HSO}_{4 \longleftarrow}^{-} \stackrel{k_{2}^{\prime}}{\rightleftarrows} \mathrm{BP}+n_{2} \mathrm{e}^{-}+x_{2} \mathrm{H}_{2} \mathrm{O} \\
\mathrm{BP} \underset{k_{3}^{\prime}}{\stackrel{k_{3}}{\rightleftarrows}} \mathrm{PN}+n_{3} \mathrm{e}^{-}+n_{3} \mathrm{H}_{3} \mathrm{O}^{+}
\end{gathered}
$$

where $k$ is the kinetic constant of expulsion, $k^{\prime}$ is the kinetic constant of insertion, $n$ represents the number of electrons or available sites inside the polymer for the insertion/expulsion of ionic species at each reaction step and $x$ is the number of water molecules exchanged during the electrochemical reactions. The redox reactions involving the anions $\left(\mathrm{HSO}_{4}^{-}\right)$and water molecules are faster than the redox reaction involving hydrated protons, in other words, $k_{1}^{\prime}>k_{3}$ and $k_{2}^{\prime}>k_{3}$ in the oxidation direction and $k_{1}>k_{3}^{\prime}$ and $k_{2}>k_{3}^{\prime}$ in the reduction direction [45].

In this work, POT films were generated in $0.5 \mathrm{M} \mathrm{H}_{2} \mathrm{SO}_{4}$ solution on gold electrodes. These films show a more open structure owing to the properties of bisulfate anions $[26,28]$. The anion composition of the $\mathrm{H}_{2} \mathrm{SO}_{4}$-structured POT films was changed by cyclic voltammetry using new and different acid solutions $\left(0.5 \mathrm{M} \mathrm{HNO}_{3}, \mathrm{HClO}_{4}\right.$ or $\mathrm{HCl}$ ). After voltammetry stabilization, the new adopted electrochemical kinetic of film was examined by ac-electrogravimetry to provide an improved understanding of the redox behavior at a POT modified electrodes. The main addressed objectives in this work are to obtain kinetic information of anions transfer during the electrochemical transitions of a $\mathrm{H}_{2} \mathrm{SO}_{4}$-structured POT film and the effect of anion identity on the transfer of other mobile species, free water molecules and hydrated protons, by impedance techniques. In addition, the different anion size can provide and highlight more evidences of the kinetic effects of conformational changes of POT films on the free solvent transfer [45]. Better understandings about the behavior of this kind of polymers front of different analytical situations, as the anion size in this case, are essential, and provide an important motivation to improve the design of technological devices based specially in sensors.

\section{2. ac-Electrogravimetry theory}

Gabrielli et al. have already explained in detail the theory of the acelectrogravimetry technique for characterizing electroactive polymers [55-59]. Here, a quick review for anion transfers is showed as an example, but a similar approach can be made for cations, solvent or the summatory of involved species $[40,60]$. 
The insertion of anions, $\mathrm{A}^{-}$, in electroactive sites during the redox reaction of host polymer $\langle\mathrm{P}\rangle$ where a single electronic transfer takes place in independent sites can be expressed as [45]:

$$
\langle\mathrm{P}\rangle+\mathrm{A}^{-} \underset{k_{\mathrm{A}^{-}}}{\stackrel{k_{\mathrm{A}^{-}}^{\prime}}{\rightleftarrows}}\left\langle\mathrm{P}^{+}, \mathrm{A}^{-}\right\rangle+\mathrm{e}^{-}
$$

where $\left\langle\mathrm{P}^{+}, \mathrm{A}^{-}\right\rangle$is the polymer matrix doped with anions. The anion transfers at the polymer|solution interface are only taken into account as rate-limiting steps since the anion transports inside the thin film and in the solution are supposed to be fast enough through thin films or enough concentrated electrolytes [56,61].

The net instantaneous molar flux change of anions, $\Delta J_{\mathrm{A}^{-}}$, when a small sine wave potential perturbation, $\Delta E$, is applied can be written as:

$$
\Delta J_{\mathrm{A}^{-}}=k_{\mathrm{A}^{-}}\left(C_{\mathrm{A}^{-}}-C_{\mathrm{A}^{-}}^{\text {min }}\right)+k_{\mathrm{A}^{-}}^{\prime}\left(C_{\mathrm{A}^{-}}^{\max }-C_{\mathrm{A}^{-}}\right) C_{\mathrm{A}^{-}}^{\text {sol }}
$$

where $C_{\mathrm{A}^{-}}$is the concentration of anions in the polymer, $C_{\mathrm{A}^{-}}^{\text {sol }}$ is the concentration of anions in the solution, $C_{\mathrm{A}^{-}}^{\max }$ is the maximum concentration of the sites available for the insertion in the polymer, $C_{\mathrm{A}^{-}}^{\text {min }}$ is the minimum concentration of the occupied sites. $k_{\mathrm{A}^{-}}$ and $k_{\mathrm{A}^{-}}^{\prime}$ are the kinetic rate constants activated by potential, $k_{\mathrm{A}^{-}}=k_{\mathrm{A}^{-} 00} \exp \left(b_{\mathrm{A}^{-}}(E-\right.$ $\left.\left.E^{0 \prime}\right)\right)$ and $k_{\mathrm{A}^{-}}^{\prime}=k_{\mathrm{A}^{-} 00} \exp \left(b_{\mathrm{A}^{-}}^{\prime}\left(E-E^{0 \prime}\right)\right)$, respectively where $E^{0 \prime}$ is the formal potential.

$b_{\mathrm{A}^{-}}$and $b_{\mathrm{A}^{-}}^{\prime}$ are the Tafel coefficients related to the number of electron involved in the faradaic process $[59,62]$ :

$$
b_{\mathrm{A}^{-}}-b_{\mathrm{A}^{-}}^{\prime}=\frac{n F}{R T}
$$

where $R$ is the gas constant and $T$ is the absolute temperature. At $298 \mathrm{~K}, n F / R T$ is about $40 \mathrm{~V}^{-1}$ for a single electron transfer $(n=1)$.

For very thin polymer films, the change of the concentration, $\Delta C_{\mathrm{A}^{-}}$, of the anion with potential $\Delta E$ can be simplified to:

$$
\frac{\Delta C_{\mathrm{A}^{-}}}{\Delta E}(\omega)=\frac{-G_{\mathrm{A}^{-}}}{j \omega d_{f}+K_{\mathrm{A}^{-}}}
$$

where $j=\sqrt{-1}, \omega$ is the angular frequency equal to $2 \pi f, f$ is the perturbation frequency and $d_{f}$ is the polymer film thickness.

$G_{\mathrm{A}^{-}}$and $K_{\mathrm{A}^{-}}$are defined from linearization of eq (5) as: 


$$
\Delta J_{\mathrm{A}^{-}}=K_{\mathrm{A}^{-}} \Delta C_{\mathrm{A}^{-}}+G_{\mathrm{A}^{-}} \Delta E
$$

So,

$$
K_{\mathrm{A}^{-}}=k_{\mathrm{A}^{-}}+k_{\mathrm{A}^{-}}^{\prime} C_{\mathrm{A}^{-}}^{\text {sol }}
$$

and

$$
G_{\mathrm{A}^{-}}=-b_{\mathrm{A}^{-}} k_{\mathrm{A}^{-}}\left(C_{\mathrm{A}^{-}}-C_{\mathrm{A}^{-}}^{m i n}\right)+b_{\mathrm{A}^{-}}^{\prime} k_{\mathrm{A}^{-}}^{\prime}\left(C_{\mathrm{A}^{-}}^{\max }-C_{\mathrm{A}^{-}}\right) C_{\mathrm{A}^{-}}^{\text {sol }}
$$

Based on this model and according to eq (7), the theoretical electrochemical impedance, $\Delta E / \Delta I(\omega)$, is [55]:

$$
\frac{\Delta E}{\Delta I}(\omega)=R_{u}+\frac{1}{j \omega C_{d l}+j \omega S d_{f} F z_{\mathrm{A}^{-}}\left[\frac{G_{\mathrm{A}^{-}}}{j \omega d_{f}+K_{\mathrm{A}^{-}}}\right]}
$$

where $R_{u}$ is the uncompensated solution resistance, $C_{d l}$ is the double layer capacity, $z_{\mathrm{A}^{-}}$ is the valence of the anion, $F$ is the Faraday constant, and $S$ is the active electrode surface area.

By subtracting the non-faradaic contributions, the electrical charge/potential transfer function, $\Delta q / \Delta E(\omega)$, can be calculated:

$$
\frac{\Delta q}{\Delta E}(\omega)=\frac{1}{j \omega} \frac{1}{\frac{\Delta E}{\Delta I}(\omega)-R_{u}}-C_{d l}
$$

and by using the eq (11) and (7), this theoretical transfer function is equal to:

$$
\frac{\Delta q}{\Delta E}(\omega)=S d_{f} F z_{\mathrm{A}^{-}}\left[\frac{G_{\mathrm{A}^{-}}}{j \omega d_{f}+K_{\mathrm{A}^{-}}}\right]
$$

Finally, the mass/potential transfer function, $\Delta m / \Delta E(\omega)$, is easily deduced from eq (7):

$$
\frac{\Delta m}{\Delta E}(\omega)=S d_{f} \delta_{\mathrm{A}^{-}} M_{\mathrm{A}^{-}}\left[\frac{G_{\mathrm{A}^{-}}}{j \omega d_{f}+K_{\mathrm{A}^{-}}}\right]
$$

where $M_{\mathrm{A}^{-}}$is the molar mass of anions involved and $\delta_{\mathrm{A}^{-}}$only reaches values of +1 because the mass decreases if the polymer is reduced. In a complex XY plot, eq (14) describes a loop on the upper right quadrant. On the contrary, if a cation exchange takes place $\delta=-1$ and the mass impedance spectrum appears on the bottom left quadrant $[56,63]$.

From eq (13) and (14), molar mass of exchanged species can be easily calculated if only one anion, in our case, is involved:

$$
F \frac{\Delta m / \Delta E}{\Delta q / \Delta E}(\omega)=F \frac{\Delta m}{\Delta q}(\omega)=\frac{\delta_{\mathrm{A}^{-}} M_{\mathrm{A}^{-}}}{z_{\mathrm{A}^{-}}}(\omega)
$$




\section{Experimental}

\subsection{Film preparation}

The electrochemical polymer deposition and characterization were controlled by cyclic voltammetry by means of an AUTOLAB potentiostat-galvanostat set up (PGSTAT302) and a lab made oscillator acted as an Electrochemical Quartz Crystal Microbalance (EQCM). The three-electrode cell involved a reference electrode (Saturated Calomel Electrode or SCE, Tacussel XR 600), a platinum counter electrode and the working electrode was a gold electrode $\left(S=0.3 \mathrm{~cm}^{2}\right)$ patterned on a $9 \mathrm{MHz}$ quartz crystal resonator (TEMEX, France). The potential of the working electrode is always referred to the SCE reference electrode. The polymerization solution was $0.5 \mathrm{M}$ $\mathrm{H}_{2} \mathrm{SO}_{4}$ (Fisher scientific, for trace analysis) and $0.2 \mathrm{M}$ o-toluidine (Fluka) used as received. POT was formed through 100 voltammetric cycles between $-0.1 \mathrm{~V}$ and $0.9 \mathrm{~V}$ vs SCE at $100 \mathrm{mV} \mathrm{s}^{-1}$ scan rate (about $40 \mu \mathrm{g} \mathrm{cm}^{-2}$ ). All the solutions were prepared with deionized and double-distilled water.

\subsection{Film characterization}

The resulting modified electrode was cycled between $-0.1 \mathrm{~V}$ and $0.9 \mathrm{~V}$ in $0.5 \mathrm{M}$ $\mathrm{HNO}_{3}$ (Normapur AnalR), in $0.5 \mathrm{M} \mathrm{HClO}_{4}$ (Normapur RP) or in $0.5 \mathrm{M} \mathrm{HCl}$ (Normapur AnalR) at $100 \mathrm{mV} \mathrm{s}^{-1}$ until a stable cyclic voltammogram was obtained (after 10 cycles in general). By this way, the complete substitution of bisulfate anions inserted in the film during the polymerization process by the new anion is assumed. $\mathrm{pH}$ is approximately 0.45 in all solutions.

After each voltammetry conditioning, ac-Electrogravimetry studies were performed at steady-state potentials ranged from $0.55 \mathrm{~V}$ to $0.05 \mathrm{~V}$. The microbalance was coupled with a four-channel frequency response analyzer (FRA, Solartron 1254) and a potentiostat (SOTELEM-PGSTAT Z1). The modified working electrode was polarized at a given potential and a sinusoidal small amplitude potential perturbation $(10 \mathrm{mV} \mathrm{rms})$ between $65 \mathrm{kHz}$ and $0.01 \mathrm{~Hz}$ was superimposed. The microbalance frequency change, $\Delta f_{m}$ and the alternating current response, $\Delta I$, were sent to the four channels FRA, which allowed the electrogravimetric transfer function, $\Delta m / \Delta E(\omega)$ and the electrochemical impedance, $\Delta E / \Delta I(\omega)$, to be simultaneously obtained. Finally, the 
fitting of the experimental data to theoretical expressions was carried out by means of an optimized version of the Levenberg-Marquardt algorithm.

\section{Results and discussion}

\subsection{General trends given by cyclic electrogravimetry}

After generating POT films in $\mathrm{H}_{2} \mathrm{SO}_{4}$ solution, the modified electrode was cycled in $\mathrm{HNO}_{3}, \mathrm{HClO}_{4}$ or $\mathrm{HCl}$ acid solutions previously to the ac-electrogravimetry experiments. In few voltammetric cycles, the films adopt the identity of the anions of new background solutions possibly due to a molecular reconfiguration of the mobile polymer chains [24]. Accordingly, three different films can be obtained with particular electrochemical properties. The cyclic voltammograms and mass changes of $\mathrm{POT}-\mathrm{Cl}^{-}$, POT-NO ${ }_{3}^{-}$and $\mathrm{POT}_{-} \mathrm{ClO}_{4}^{-}$films are given in Figure 1.

The voltammograms always show two redox couples associated to the transfer of anions and protons to balance the excess of charge as those reported in the literature $[36,64]$. On the one hand, the couple of peaks observed around $0.2 \mathrm{~V}$ correspond to the $\mathrm{LE} \rightleftarrows \mathrm{P}$ transitions (eq (1)). In this range of potentials, the evaluation of the instantaneous slope of the mass/charge profile shows positive values of effective molar mass between $10-80 \mathrm{~g} \mathrm{~mol}^{-1}$ owing to the anions transfer (not showed here). These values are always lower than the corresponding anions in solutions $\left(M_{\mathrm{Cl}^{-}}=35.5 \mathrm{~g} \mathrm{~mol}^{-1}, M_{\mathrm{NO}_{3}^{-}}=62 \mathrm{~g} \mathrm{~mol}^{-1}\right.$ or $\left.M_{\mathrm{ClO}_{4}^{-}}=99.5 \mathrm{~g} \mathrm{~mol}^{-1}\right)$. A counter flux of free water molecules per anion could explain this behavior also called exclusion effect [45]. On the other hand, the couple of peaks close to $0.4 \mathrm{~V}$ show the evolution of the $\mathrm{BP} \rightleftarrows \mathrm{PN}$ transitions (eq (3)). Now, the mass/charge profile has a slope around $-10 \mathrm{~g} \mathrm{~mol}^{-1}$ close to the molar mass of hydrated protons $\left(M_{\mathrm{H}_{3} \mathrm{O}^{+}}=19 \mathrm{~g} \mathrm{~mol}^{-1}\right)$. A lower value than $18 \mathrm{~g} \mathrm{~mol}^{-1}$ can be due to overlapped anions transfers of the $\mathrm{P} \rightleftarrows \mathrm{BP}$ transitions (eq (2)) which takes place at intermediate potentials without apparent redox couple and with positive values of the charge/mass slope (coupled anion/water transfer). This last transition can be discerned by absorbance changes around $700 \mathrm{~nm}$ during the cyclic voltammetry [64,65] or from acelectrogravimetry [45]. 


\subsection{Degradation effect and potential selection}

Previous results were essentials to start the subsequent kinetic study of POT by impedance-based techniques as ac-electrogravimetry. On the one hand, the degradation by hydrolysis of this kind of films is well-known owing to an over oxidation step at anodic potentials [66-68]. In our experimental conditions, Figure 1 does not show significant changes of mass in $\mathrm{HClO}_{4}$ and $\mathrm{HNO}_{3}$ solutions between $0.7 \mathrm{~V}$ and $0.9 \mathrm{~V}$. In similar conditions, the degradation of this kind of films was proved clearly by bidimensional spectroscopy beyond $0.9 \mathrm{~V}$ vs. $\mathrm{Ag} / \mathrm{AgCl} / \mathrm{KCl}$ (3 $\mathrm{M}$ ) [69]. On the contrary, the increase of intensity between 0.7 and $0.9 \mathrm{~V}$ in $\mathrm{HCl}$ solution is accompanied by a mass decrease possibly due to a small film hydrolysis. This hydrolysis slightly reduces only $0.5 \mu \mathrm{g} \mathrm{cm}^{-2}$ the amount of film deposited through the voltammetric cycles of stabilization (10 cycles). This fact does not affect the electrochemically useful information obtainable by ac-electrogravimetry because the oxidation peaks does not change significantly during the stabilization. On the other hand, hydrogen evolution and formation of hydrogen bubbles on the electrode surface can affect seriously the electrogravimetry results given by the microbalance at cathodic potentials in these experimental conditions. By considering this, ac-electrogravimetry experiments were performed at potentials below $0.7 \mathrm{~V}$ in order to avoid the irreversible loss of film by hydrolysis and above $0 \mathrm{~V}$ in order to avoid a significant hydrogen evolution.

\subsection{Kinetic model}

$<$ Figure $2>$

Figure 2 shows the evolution of both experimental transfer functions $(\Delta q / \Delta E(\omega)$ and $\Delta m / \Delta E(\omega))$ obtained by ac-electrogravimetry at some representative potentials for the POT-NO- $\mathrm{NOT}_{3}^{-} \mathrm{ClO}_{4}^{-}$and POT-Cl- films.

Only from electrochemical impedance spectroscopy, two different charge transfers (one fast and one slow) can be discriminated at $0.4 \mathrm{~V}$ in the $\mathrm{POT}_{-} \mathrm{ClO}_{4}^{-}$film as Figure 2c shows. In POT- $\mathrm{NO}_{3}^{-}$and POT-Cl- films, only one charge transfer is observed in the experimental data of $\Delta q / \Delta E(\omega)$ at all polarization potentials applied (Figure 2a and e). The fastest process of $\Delta q / \Delta E(\omega)$ in Figure $2 \mathrm{a}, \mathrm{c}$ and e can be associated with the anion transfer since the experimental data of $\Delta m / \Delta E(\omega)$ at high frequencies appear 
on the upper right quadrant in Figure $2 \mathrm{~b}, \mathrm{~d}$ and $\mathrm{f}$. In all films, the fast anion transfer should be implied in the fast charge balance as counter-ion. On the contrary, the slowest processes in $\Delta q / \Delta E(\omega)$ correspond to the opposite transfer of hydrated protons since the experimental results at lower frequencies are located on the bottom right (at $0.4 \mathrm{~V}$ in Figure $2 \mathrm{~d}$ ) or on the bottom left quadrants (at $0.5 \mathrm{~V}$ in Figure $2 \mathrm{~b}, \mathrm{~d}$, and $\mathrm{f}$ ). In spite of $\mathrm{H}_{3} \mathrm{O}^{+}$is the smallest ion, the chemical protonation/deprotonation of electroactive sites during the hopping between donors and acceptors amine groups in the polymer backbone similar to the Grotthuss mechanism would slow the $\mathrm{H}_{3} \mathrm{O}^{+}$transfer in the polymer|solution interface during the $\mathrm{BP} \rightleftarrows \mathrm{PN}$ transitions $[42,70,71]$. The simultaneous analysis of both transfer function is very useful to confirm more than one contribution in the charge transfer process.

\section{$<$ Figure 3 $>$}

From the mass/charge transfer function (eq. (15)), the experimental apparent molar mass of exchanged species in ac regime are calculated. Figure 3 shows the evolution of $F \Delta m / \Delta q(\omega)$ at lower frequency perturbation $(10 \mathrm{mHz})$. In this manner, faster and slower processes are involved and can be evaluated. Like in voltammetry, the positive values are between $0.05 \mathrm{~V}$ and $0.4 \mathrm{~V}$ where $\mathrm{LE} \rightleftarrows \mathrm{P} \rightleftarrows \mathrm{BP}$ transitions are expected. The obtained values lower than the molar mass of the corresponding anion confirm the counter flux of water molecules even in steady-state conditions. On the contrary, the experimental mass/charge transfer function is negative between 0.4 and $0.55 \mathrm{~V}$ where $\mathrm{BP} \rightleftarrows \mathrm{PN}$ transitions take place due to the transfer of hydrated protons. If there were a degradation of the polymer by hydrolysis at $0.55 \mathrm{~V}, F \Delta m / \Delta q(\omega)$ would show higher values than $-20 \mathrm{~g} \mathrm{~mol}^{-1}$ because the molar mass of one monomer of otoluidine is about $107 \mathrm{~g} \mathrm{~mol}^{-1}$. The results prove sufficiently the stability of film at the studied potential range in ac-electrogravimetry.

Accordingly, three species transfers (two charged species and one non-charged) during the electrochemical reactions of the three POT films can be considered. Firstly, kinetic parameters, where only charged species participate, are obtained from fitting, based on eq (13) of the experimental data, $\Delta q / \Delta E(\omega)$. For that, the following modifications of theoretical equation were carried out:

$<$ Table 1>

i) A quasi-vertical branch was observed at more cathodic potentials in all films (i.e. inset of Figure 2a) for low frequencies. This indicates the presence of a little 
contribution of hydrogen evolution. To eliminate this charge contribution, a $R_{p}, C_{p}$ series circuit is added to eq (13). As it was expected for a cathodic reaction, $C_{p}$ increases, and $R_{p}$ decreases to more cathodic potentials (Table 1).

ii) The calculation of thickness from charge data does not always offer an indisputable evidence because all electroactive sites along the polymeric chain of polymer are not necessarily oxidized or reduced [72-74]. Moreover, the thickness of film may change depending on the polarization potential [75-79]. As a result, the thickness of resultant polymers was not so easily estimated and for this reason, an apparent kinetic parameter $K^{\prime}=K / d_{f}$ was used instead. Accordingly, $j \omega d_{f}$ was also rewritten such as $j \omega$.

iii) Eq (13) defines a perfect semicircle on the impedance plan plot characteristic of uniform surface of films when $\alpha=1$ in $(j \omega)^{\alpha}$. Sometimes, experimental results show depressed semicircles. This discrepancy is phenomenological replicated in this field by using the constant-phase element $(\alpha \neq 1)$. Many factors can affect the values of $\alpha$ as it was explained in ref [45]. As the physical meaning of this element is not clear, $(j \omega)^{\alpha}$ is mathematically used to achieve the best fittings in this work. $\alpha$ values close to an ideal system $(\alpha \approx 0.9)$ for all involved species were obtained.

In view of that, $\Delta q / \Delta E(\omega)$ theoretical transfer function (in $\mathrm{C} \mathrm{cm}^{-2} \mathrm{~V}^{-1}$ ), in case of a single cation and anion contribution, is such as:

$$
\frac{\Delta q}{\Delta E}(\omega)=F\left[\frac{z_{\mathrm{A}^{-}} G_{\mathrm{A}^{-}}}{(j \omega)^{\alpha_{\mathrm{A}^{-}}}+K_{\mathrm{A}^{-}}^{\prime}}+\frac{z_{\mathrm{H}_{3} \mathrm{O}^{+}} G_{\mathrm{H}_{3} \mathrm{O}^{+}}}{(j \omega)^{\alpha_{\mathrm{H}_{3} 0^{+}}+K_{\mathrm{H}_{3} \mathrm{O}^{+}}^{\prime}}}\right]+\frac{1}{R_{p}+\frac{1}{j \omega C_{p}}}
$$

where $z_{\mathrm{A}^{-}}=Z_{\mathrm{H}_{3} \mathrm{O}^{+}}=1$ and $\mathrm{A}^{-}$may be $\mathrm{NO}_{3}^{-}, \mathrm{ClO}_{4}^{-}$or $\mathrm{Cl}^{-}$depending on background solution.

Once the best-fit parameters values are obtained by fitting of the theoretical transfer function given by eq (16) to the experimental $\Delta q / \Delta E(\omega)$, they are fixed in the next equation for the fittings of experimental $\Delta m / \Delta E(\omega)$ (in $\mathrm{g} \mathrm{cm}^{-2} \mathrm{~V}^{-1}$ ). Taking into account the considerations ii and iii, eq (14) can be modified to obtain the electrogravimetric transfer function where, in addition, the free solvent transfer is also considered:

$$
\frac{\Delta m}{\Delta E}(\omega)=\frac{\delta_{\mathrm{A}^{-}} M_{\mathrm{A}^{-}} G_{\mathrm{A}^{-}}}{(j \omega)^{\alpha_{\mathrm{A}^{-}}}+K_{\mathrm{A}^{-}}^{\prime}}+\frac{\delta_{\mathrm{H}_{3} \mathrm{O}^{+}} M_{\mathrm{H}_{3} \mathrm{O}^{+}} G_{\mathrm{H}_{3} \mathrm{O}^{+}}}{(j \omega)^{\alpha_{\mathrm{H}_{3} 0^{+}}}+K_{\mathrm{H}_{3} \mathrm{O}^{+}}^{\prime}}+\frac{\delta_{\mathrm{H}_{2} \mathrm{O}} M_{\mathrm{H}_{2} \mathrm{O}} G_{\mathrm{H}_{2} \mathrm{O}}}{(j \omega)^{\alpha_{\mathrm{H}_{2} 0}}+K_{\mathrm{H}_{2} \mathrm{O}}^{\prime}}
$$

The transfer direction and molar masses $\left(\delta_{i} M_{i}\right)$ of species can also be fixed taking into account the results of Figure 3. Then, $\delta_{\mathrm{Cl}^{-}}=\delta_{\mathrm{NO}_{3}^{-}}=\delta_{\mathrm{ClO}_{4}^{-}}=+1$ which means that 
the anions ions leave the polymer during the reduction. Meanwhile, $\delta_{\mathrm{H}_{3} \mathrm{O}^{+}} M_{\mathrm{H}_{3} \mathrm{O}^{+}}$is -19 $\mathrm{g} \mathrm{mol}^{-1}$ owing to the insertion of hydrated protons during the reduction. The transfer direction and molar mass of free solvent was also fixed as $\delta_{\mathrm{H}_{2} \mathrm{O}} M_{\mathrm{H}_{2} \mathrm{O}}=-18 \mathrm{~g} \mathrm{~mol}^{-1}$ assuming the exclusion effect promoted by the anion transfer. So, only these parameters concerning to the free solvent had to be found from fittings. The continuous lines in Figure 2 for all films show a very accurate fittings of eq (16) and (17) considering the proposed model.

However, we have not found good correlations between both transfer functions from $0.35 \mathrm{~V}$ to $0.2 \mathrm{~V}$ in POT-Cl ${ }^{-}$films with the proposed model. At $0.3 \mathrm{~V}$ in $\mathrm{HCl}$ solutions, the real part of $F \Delta m / \Delta q(\omega)$ takes values above $M_{\mathrm{Cl}^{-}}$indicating the insertion of anions with water molecules between $160 \mathrm{mHz}$ and $40 \mathrm{~Hz}$ of perturbation frequency (not showed here). On the contrary, $F \Delta m / \Delta q(\omega)$ is lower than $M_{\mathrm{Cl}^{-}}$at lower frequency perturbations (Figure 3). Therefore, a more complex mechanism should be considered at these potentials for the POT-Cl' film.

This last fact was not observed in previous work where $a c$-electrogravimetry of polyaniline in $\mathrm{HCl}$ solutions has shown good results at all polarization potentials [43]. In this case, the generated film in $\mathrm{HCl}$ solutions has probably ionic channels adapted to the size of $\mathrm{Cl}^{-}$. Here, the ionic channels are formed from the template leaving by $\mathrm{HSO}_{4}^{-}$ during the electrogeneration, for this reason, the film shows an open structure and not adapted to the size of $\mathrm{Cl}^{-}$. The effects of the molecular arrangements on the species transfers would be shown more clearly in these conditions, as it will be commented below. Consequently, let us consider this special transfer model to future works with the intention not to extend the discussion of the results presented here. Thus, we discuss only the few kinetic results of POT- $\mathrm{Cl}^{-}$films at the potentials where both transfer functions have been correlated with the theoretical kinetic model proposed here, eq (16) and (17).

\subsection{Localization of electrochemical reactions on potential scale}

The electrochemical transitions of POT films at steady-state conditions can be placed on the potential scale by means of the derivative of the surface insertion laws $d \Gamma_{i}(E) / d E$ for each species transfers obtained from the $G_{i} / K_{i}^{\prime}$ ratios [45]. The peaks have the same meaning as the theoretical derivation of a voltammetric response of an 
electrochemical process but, in this case, they correspond to the transfer of only one specie associated to one electrochemical transition. Figure 4 shows $d \Gamma_{i}(E) / d E$ of POT$\mathrm{NO}_{3}^{-}$and POT-ClO $-\mathrm{Pilms}_{4}$. Unfortunately, this could not be done from the few data of POT-Cl- film.

Theoretically, $d \Gamma_{i}(E) / d E$ (in mol cm $\mathrm{cm}^{-2} \mathrm{~V}^{-1}$ ) peaks for each one of the $i$ species can be defined as $[43,45,80]$ :

$$
\frac{G_{i}}{K_{i}^{\prime}}(E)=\frac{d \Gamma_{i}}{d E}(E)=\frac{b_{i}-b_{i}^{\prime}}{4} \frac{\Gamma_{i}^{\max }-\Gamma_{i}^{\min }}{\cosh ^{2}\left[\frac{b_{i}-b_{i}^{\prime}}{2}\left(E-E_{p, i}\right)\right]}
$$

where $\Gamma_{i}^{\max }$ is the maximum surface concentration of the sites available for the insertion in the polymer, $\Gamma_{i}^{\text {min }}$ is the minimum surface concentration of the sites occupied and $E_{p, i}$ is the peak potential where $d \Gamma_{i}(E) / d E$ is higher. If $\Gamma_{i}^{\min }$ is assumed as $0 \mathrm{~mol} \mathrm{~cm}{ }^{-2}$, information about $b_{i}-b_{i}^{\prime}, \Gamma_{i}^{\max }$ and $E_{p, i}$ can be easily found by fitting the experimental results with eq (18) for each transfer process by taking into account previous data [65]. Table 2 and Table 3 summarize the parameters obtained by the fitting procedure and the continuous lines in Figure 4 are the resulting fitted curves.

\section{$<$ Figure $4>$ \\ $<$ Table 2> \\ $<$ Table 3>}

As the polarization potentials were applied from $0.55 \mathrm{~V}$ to $0.05 \mathrm{~V}$, we can consider the reduction of films to facilitate the discussion of results. In a POT- $\mathrm{NO}_{3}^{-}$film (Figure $4 \mathrm{a}$ ), the first redox reaction corresponds to the $\mathrm{PN} \rightarrow \mathrm{BP}$ transition around $0.55 \mathrm{~V}$ with the participation of $\mathrm{H}_{3} \mathrm{O}^{+}$. Next, the $\mathrm{BP} \rightarrow \mathrm{P}$ transition occurs at $0.43 \mathrm{~V}$ and finally the $\mathrm{P} \rightarrow \mathrm{LE}$ transition takes place around $0.11 \mathrm{~V}$ with the participation of $\mathrm{NO}_{3}^{-}$and free water transfer.

In $\mathrm{POT}_{-} \mathrm{ClO}_{4}^{-}$films, the anions inserted in the structure of polymer affects the order in which the electrochemical reactions occur. The $\mathrm{PN} \rightarrow \mathrm{BP}$ transition takes place around $0.44 \mathrm{~V}$ (Figure $4 \mathrm{~b}$ ); however, the more anodic peak of $\mathrm{ClO}_{4}^{-}$and free water transfers associated to $\mathrm{BP} \rightarrow \mathrm{P}$ transition take place previously, around $0.49 \mathrm{~V}$ (Figure $4 \mathrm{~d}$ and $\mathrm{f}$ ). In the voltammetric responses of the films (Figure 1), the mass increases in the reduction direction owing to the insertion of $\mathrm{H}_{3} \mathrm{O}^{+}$in POT- $\mathrm{NO}_{3}^{-}$films. 
On the contrary, a constant mass is observed in the reduction of POT-ClO- ${ }_{4}^{-}$film between $0.9 \mathrm{~V}$ and $0.4 \mathrm{~V}$. This overlapping explains the shape (soft) of the more anodic voltammetric peak in the reduction direction with respect to the sharp shapes observed by other films.

Finally, the second expulsion of $\mathrm{ClO}_{4}^{-}$and insertion of $\mathrm{H}_{2} \mathrm{O}$ takes place together with a smaller and slow $\mathrm{H}_{3} \mathrm{O}^{+}$transfer around $0.1 \mathrm{~V}$ where the $\mathrm{P} \rightarrow \mathrm{LE}$ transition is expected. This $\mathrm{H}_{3} \mathrm{O}^{+}$transfer could not be observed by fast cyclic spectroelectrogravimetry in the similar experimental conditions [81]. However, Hillman et al. observed a $\mathrm{H}_{3} \mathrm{O}^{+}$transfer during the $\mathrm{LE} \rightleftarrows \mathrm{P}$ transition of POT-ClO- $\mathrm{P}_{4}^{-}$films working at lower $\mathrm{pH}$ [37]. The strong interactions between anions and POT and the different chemical properties of anions could explain the differences between POT-ClO- films and other films like POT-NO $\mathrm{N}_{3}^{-}$film or POT-HSO ${ }_{4}^{-}$films of ref [45].

On the one hand, $\mathrm{ClO}_{4}^{-}$are more hydrophobic than $\mathrm{NO}_{3}^{-}$or $\mathrm{Cl}^{-}$following the Hofmeister series of anions [82]. Around $0.5 \mathrm{~V}$, the insertion of hydrated protons during the $\mathrm{PN} \rightarrow \mathrm{BP}$ transition and the expulsion of anions during the $\mathrm{BP} \rightarrow \mathrm{P}$ transition increase the hydration degree of POT film. Moreover, deprotonated PN sites can be chemically protonated by means of acid/base equilibrium to form BP sites $[83,84]$. These facts could be the cause of the expulsion of these anions at more anodic potentials.

On the other hand, the $\mathrm{H}_{3} \mathrm{O}^{+}$transfer around $0.1 \mathrm{~V}$ could be due to the packing of films. Degradation studies of similar polymers doped with different anions have shown their great affinity with $\mathrm{ClO}_{4}^{-}$ions $[34,68]$.The width of peaks characterized by $b_{i}-b_{i}^{\prime}$ is around $20 \mathrm{~V}^{-1}$. Up to day, we still have difficulties to give an explanation of this result since the existence of a previous chemically controlled step of the singleelectron transfers [85] or considering the apparent transfer of half electron during the electrochemical reaction may also be considered with the same numerical result in eq (6). However, lower values than the theoretical value of $40 \mathrm{~V}^{-1}$ can also indicate an increase of lateral interactions between random distributed electroactive sites during the electrochemical reactions of film assuming a Frumkin-type isotherm [81,86-89]. Values of $b_{i}-b_{i}^{\prime}$ parameter point out this fact since $b_{i}-b_{i}^{\prime}$ of $\mathrm{ClO}_{4}^{-}$always has a lower value than this quantity for $\mathrm{NO}_{3}^{-}$in both $\mathrm{BP} \rightarrow \mathrm{P}$ and $\mathrm{P} \rightarrow \mathrm{LE}$ transitions. The polymer-anion 
interactions in $\mathrm{POT}_{-} \mathrm{ClO}_{4}^{-}$films constrain polymer chain dynamics increasing the stiffness of film with respect other doping anions [24]. Moreover, the formation of coil structures during this transition could hinder the transport of the tetrahedral anions inside the film in spite of hydrated film at $0.1 \mathrm{~V}$ [81]. Thus, the charge would be balanced by the entry of $\mathrm{H}_{3} \mathrm{O}^{+}$as a counter-ion during the $\mathrm{P} \rightarrow \mathrm{LE}$ transition because a small number of $\mathrm{ClO}_{4}^{-}$could not exit from the packed polymer. In this occasion, $\mathrm{H}_{3} \mathrm{O}^{+}$ would not act as a reactant ion as it occurs during the $\mathrm{PN} \rightarrow \mathrm{BP}$ transition. Consequently, $\mathrm{ClO}_{4}^{-}$inserted in the POT increases the amount of $\mathrm{H}_{3} \mathrm{O}^{+}$transfer, total $\Gamma_{\mathrm{H}_{3} \mathrm{O}^{+}}^{\max }=29 \mathrm{nmol}$ $\mathrm{cm}^{-2}$, in comparison with $\mathrm{NO}_{3}^{-}$where $\Gamma_{\mathrm{H}_{3} \mathrm{O}^{+}}^{\max }=19 \mathrm{nmol} \mathrm{cm}^{-2}$ (Table 2 and Table 3).

The spatial distribution of anions inside the film was found different taking into account the results of $\Gamma_{\mathrm{NO}_{3}^{-}}^{\max }$ and $\Gamma_{\mathrm{ClO}_{4}^{-}}^{\text {max }}$ in Table 2 and Table 3 respectively. $\mathrm{ClO}_{4}^{-}$anions inserted in the film allow a similar amount of P $\left(25 \mathrm{nmol} \mathrm{cm} \mathrm{cm}^{-2}\right)$ or BP $\left.(31 \mathrm{nmol} \mathrm{cm})^{-2}\right)$ sites. On the contrary, bipolaron form is preferred in presence of $\mathrm{NO}_{3}^{-}\left(46 \mathrm{nmol} \mathrm{cm}^{-2}\right)$ than polaron form $\left(28 \mathrm{nmol} \mathrm{cm}{ }^{-2}\right)$. The addition of both quantities shows that $\mathrm{NO}_{3}^{-}$ allows more sites to be electroactive $\left(76 \mathrm{nmol} \mathrm{cm}^{-2}\right)$ than $\mathrm{ClO}_{4}^{-}$allows $\left(56 \mathrm{nmol} \mathrm{cm} \mathrm{cm}^{-2}\right)$ in the film because smaller anions reduce the separation between electroactive sites [23]. However, dealing with how the anion size influences the stability of polarons or bipolarons needs more and further studies to clarify. On the other hand, $\Gamma_{\mathrm{H}_{2} \mathrm{O}}^{\max }$ in both electrochemical transitions are similar in both films independently of the size of anion inserted (about $115 \mathrm{nmol} \mathrm{cm}$ in the $\mathrm{BP} \rightarrow \mathrm{P}$ transition and about $55 \mathrm{nmol} \mathrm{cm}$ in the $\mathrm{P} \rightarrow \mathrm{LE}$ transition). The exclusion effect by anions is not a pure process during the free water transfer, as it will be discussed below.

\subsection{Easiness of species transfer at the polymer|solution interface}

\section{$<$ Figure 5 $>$}

$G_{i}$ could be mathematically interpreted as the inverse of a charge transfer resistance at the polymer|solution interface, $1 / F G=R_{c t}$ [90]. It refers to the easiness of the transfer of species during the electrochemical reactions of POT films. Figure 5 shows the variation of $G_{i}$ with respect to the potential for all the involved species in these three films. As it can be seen, $G_{i}$ curves show a peak-shaped evolution for POT- 
$\mathrm{NO}_{3}^{-}$and $\mathrm{POT}-\mathrm{ClO}_{4}^{-}$films. For anions and free water transfers, two peaks should be expected because both species are involved in two different electrochemical processes (Figure 4). However, anions and solvent transfers show only one peak of $G_{i}$ centered at $0.3 \mathrm{~V}$. This particular behavior is explained if we consider that the same species can be inserted in two different sites in the structure of the film ( $\mathrm{P}$ and $\mathrm{BP}$ form) as it was theoretically exposed in ref [45]. Thus, the easiness of specie transfers during the $\mathrm{P} \rightarrow \mathrm{LE}$ transition are $G_{i}$ values between $0.05 \mathrm{~V}$ to $0.3 \mathrm{~V}$, on the other side of peak, $G_{i}$ values correspond to $\mathrm{BP} \rightarrow \mathrm{P}$ transition.

Using the commercial software ChemBio3D Ultra v. 12.0 ChemBioOffice 2010, the volume of anions can be estimated from the Connolly Solvent Excluded Volume. The volume of $\mathrm{ClO}_{4}^{-}$is about $47 \AA^{3}$, about $32 \AA^{3}$ for $\mathrm{NO}_{3}^{-}$, about $29 \AA^{3}$ for $\mathrm{Cl}^{-}$and about $10 \AA^{3}$ for $\mathrm{H}_{3} \mathrm{O}^{+}$and water molecules. The easiness of anions to cross the polymer|solution interface is strongly affected by the kind of the involved charged species. The easiness decreases in the order $G_{\mathrm{Cl}^{-}}>G_{\mathrm{NO}_{3}^{-}}>G_{\mathrm{ClO}_{4}^{-}} . G_{\mathrm{NO}_{3}^{-}}$is 2-3 times higher than $G_{\mathrm{ClO}_{4}^{-}}$at all polarization potentials. This is not in accordance with the $\mathrm{ClO}_{4}^{-} / \mathrm{NO}_{3}^{-}$ volume ratio $\left(V_{\mathrm{ClO}_{4}^{-}} / V_{\mathrm{NO}_{3}^{-}} \approx 1.5\right)$. Likewise, $G_{\mathrm{Cl}^{-}}$is 2-3 times higher than $G_{\mathrm{NO}_{3}^{-}}$at same potentials and this does not correspond with the $\mathrm{NO}_{3}^{-} / \mathrm{Cl}^{-}$volume ratio $\left(V_{\mathrm{NO}_{3}^{-}} / \mathrm{Cl}_{\mathrm{Cl}^{-}} \approx 1.1\right)$.

The open structure of $\mathrm{H}_{2} \mathrm{SO}_{4}$-structured POT is associated with a great hydration of film facilitating the chain motions and generating a low viscosity medium where anions can move freely [24]. However, the size cannot explain by itself these results. These can be explained based on the molecular geometry of anions. By taking into account that the POT film has the same structure, the tetrahedral molecular geometry of $\mathrm{ClO}_{4}^{-}$could involve more transfer difficulties than the trigonal planar molecular geometry of $\mathrm{NO}_{3}^{-}$to cross the polymer|solution interface during the $\mathrm{BP} \rightarrow \mathrm{P}$ and $\mathrm{P} \rightarrow \mathrm{LE}$ transitions. In $\mathrm{HCl}$ solutions, the spherical and monoatomic nature of $\mathrm{Cl}^{-}$ allows the easiness transfer to be achieved at the studied polarization potentials in spite of the similar size between $\mathrm{NO}_{3}^{-}$and $\mathrm{Cl}^{-}$.

Our model allows the effects of anion size on the transfer of other species to be also quantified. On the one hand, the free solvent transfer is noticeably easier in POT- 
$\mathrm{NO}_{3}^{-}$films than in $\mathrm{POT}-\mathrm{ClO}_{4}^{-}$films at all polarization potentials and mainly at $0.3 \mathrm{~V}$ (Figure 5b). The tetrahedral $\mathrm{ClO}_{4}^{-}$further hinders the free water transfer than planar $\mathrm{NO}_{3}^{-}$. However, the free solvent has more difficulties to cross the polymer|solution interface in in the POT-Cl ${ }^{-}$films between 0.05 and $0.15 \mathrm{~V}(\mathrm{P} \rightarrow \mathrm{LE}$ transition). The small $\mathrm{H}_{3} \mathrm{O}^{+}$transfer detected at these potentials can affect $G_{\mathrm{H}_{2} \mathrm{O}}$. On the contrary, the easiness of free solvent is slightly higher than $G_{\mathrm{H}_{2} \mathrm{O}}$ of POT- $\mathrm{NO}_{3}^{-}$film at potentials close to 0.4$0.45 \mathrm{~V}\left(\mathrm{BP} \rightarrow \mathrm{P}\right.$ transition). In this occasion, the molecular geometry of inserted $\mathrm{Cl}^{-}$ cannot explain these results.

Hydrated protons transfer has an upper limit at about $0.5-0.4 \mathrm{~V}$ as shown in Figure 5c. In POT-NO ${ }_{3}^{-}$and POT-ClO ${ }_{4}^{-}$films, $G_{\mathrm{H}_{3} \mathrm{O}^{+}}$has a similar maximum value about $0.13 \mu \mathrm{mol} \mathrm{s} \mathrm{cm}^{-2} \mathrm{~V}^{-1}$. However, proton transfer occurs only around $0.45 \mathrm{~V}$ in POT$\mathrm{NO}_{3}^{-}$film whereas it takes place in the larger potential range for POT-ClO- film. The proton transfer in the POT-Cl ${ }^{-}$film seems to be in a wide range of potentials like in POT-ClO- film but $G_{\mathrm{H}_{3} \mathrm{O}^{+}}$reaches the highest values when it is compared among all films around $0.5 \mathrm{~V}(\mathrm{PN} \rightarrow \mathrm{BP}$ transition) and around $0.1 \mathrm{~V}(\mathrm{P} \rightarrow \mathrm{LE}$ transition). The molecular geometry of inserted $\mathrm{Cl}^{-}$favors an easier transfer of $\mathrm{H}_{3} \mathrm{O}^{+}$.

\subsection{Rate of species transfer at the polymer|solution interface}

\section{$<$ Figure 6>}

Figure 6 shows the potential dependence of $K_{i}^{\prime}$ for the three films. This parameter is related to the kinetic constants of the electrochemical reactions (eq. (9)) and is mathematically interpreted as the inverse of time constant $(1 / R C)$. As it was expected, the results show that the smallest anion is the faster one and the series is $K_{\mathrm{Cl}^{\prime}}^{\prime}>K_{\mathrm{NO}_{3}^{-}}^{\prime}>K_{\mathrm{ClO}_{4}^{-}}^{\prime}$ because the nature of anions influences the motion of charge carriers ( $\mathrm{P}$ or $\mathrm{BP}$ ) along the chains [33]. The results show that $\mathrm{NO}_{3}^{-}$is always transferred faster than $\mathrm{ClO}_{4}^{-}$at all the studied polarization potentials. Here, $\mathrm{K}_{\mathrm{NO}_{3}^{-}}^{\prime} / \mathrm{K}_{\mathrm{ClO}_{4}^{-}}^{\prime}$ ratio is about 1.6 and it is in accordance with the $\mathrm{NO}_{3}^{-} / \mathrm{ClO}_{4}^{-}$volume ratio $\left(V_{\mathrm{ClO}_{4}^{-}} / V_{\mathrm{NO}_{3}^{-}} \approx 1.5\right)$ but $K_{\mathrm{Cl}^{\prime}}^{\prime} / K_{\mathrm{NO}_{3}^{-}}^{\prime}$ ratio is about 2 and it does not correspond with $V_{\mathrm{NO}_{3}^{-}} / V_{\mathrm{Cl}^{-}} \approx 1$.1. Here, the 
spherical monoatomic nature of $\mathrm{Cl}^{-}$enhances the rate of transfer to cross the polymer|solution interface in spite of the similar size and mobility. It is possible that the anion size influences the rate of transfer only when polyatomic anions participate in the charge balance of POT.

Likewise, the smallest anion allows the faster free water transfer to be achieved. The POT- $\mathrm{NO}_{3}^{-}$film allows the free water transfer to be about 2-4 times faster than the POT-ClO ${ }_{4}^{-}$film depending on potential. However, the free water transfer is not significant faster in $\mathrm{POT}_{-} \mathrm{Cl}^{-}$films than $\mathrm{POT}-\mathrm{NO}_{3}^{-}$during the $\mathrm{LE} \rightarrow \mathrm{P}$ transition (between $0.05 \mathrm{~V}$ and $0.15 \mathrm{~V}$ ). On the contrary, POT films with $\mathrm{Cl}^{-}$stored inside allow the water transfer to be faster (about twice) during the $\mathrm{P} \rightarrow \mathrm{BP}$ transition $(0.4-0.5 \mathrm{~V}$ ) with respect to POT-NO ${ }_{3}^{-}$film. The fast transfer of free water molecules explain the results reported in previous works because a pure anion transfer cannot be reached at the experimental time scales [36].

The hydrated proton transfer is kinetically similar in all films with an upper limit of $K_{\mathrm{H}_{3} \mathrm{O}^{+}}^{\prime}$ about $3 \mathrm{~s}^{-1}$ and it can be considered like an anion-independent mechanism. The protonation/deprotonation of sites during the $\mathrm{PN} \rightleftarrows \mathrm{BP}$ transitions has not be influenced by the anions in solution owing to the small size of $\mathrm{H}_{3} \mathrm{O}^{+}$. The Grotthuss mechanism proposed to this process to the transport of protons inside the film could be the ratelimiting step of this transfer. The anion in solution affects the potentials where the fastest $\mathrm{H}_{3} \mathrm{O}^{+}$transfer takes place. Like in $G_{i}$ results, the maximum transfer rate of the hydrated proton is centered at $0.45 \mathrm{~V}$ in $\mathrm{POT}_{-\mathrm{NO}_{3}^{-}}$films. On the contrary, the proton transfer takes place in a wide range of potentials in the POT-ClO ${ }_{4}^{-}$film and it could be also assumed in POT- $\mathrm{Cl}^{-}$films. In spite of the double role of $\mathrm{H}_{3} \mathrm{O}^{+}$commented for the POT-ClO- ${ }_{4}^{-}$films, the $\mathrm{H}_{3} \mathrm{O}^{+}$transfer shows similar kinetic rates during the $\mathrm{PN} \rightarrow \mathrm{BP}$ transition (around $0.5 \mathrm{~V}$ ) and the $\mathrm{P} \rightarrow \mathrm{LE}$ transition (around $0.1 \mathrm{~V}$ ).

\subsection{Additional factor affecting the free solvent transfer}

Hillman et al. have suggested a slow-moving solvent counter flux with a fast anion exchange for the POT films in $\mathrm{HClO}_{4}$ solution [36]. However, the results by acelectrogravimetry points to a fast transfer of water molecules influenced by the anions 
in solution. The smaller and planar anion $\left(\mathrm{NO}_{3}^{-}\right)$would not block the water transfer as larger $\mathrm{ClO}_{4}^{-}$ions do since $G_{\mathrm{H}_{2} \mathrm{O}}$ in the POT- $\mathrm{NO}_{3}^{-}$film is higher than in POT-ClO- film. $\mathrm{Cl}^{-}$does not affect the water transfer to satisfy activity constraints during the $\mathrm{P} \rightarrow \mathrm{LE}$ transition around $0.1 \mathrm{~V}$ and for this reason, $G_{\mathrm{H}_{2} \mathrm{O}}$ shows the lower values. However, the smaller size of $\mathrm{Cl}^{-}$allows the water transfer to be easier than other anions when a number of $\mathrm{Cl}^{-}$is already inside the film at $0.4-055 \mathrm{~V}$.

Transfer of neutral solvent, as free water molecules, there is no a priori relationship with the injected charge (kinetically controlled conditions) and can be controlled by a non-ideal thermodynamic behavior (non-linear film solvation with charge state) [91,92]. Here, the exit of large enough anions from POT leaves vacancies, which can be occupied rapidly by incoming free solvent molecules during the reduction reactions [45]. In POT-ClO this fact. Therefore, the water transfer is kinetically controlled through the anion transfer when the anion is large enough or at particular potentials.

However, some results point to a different process kinetically controlled, which could affect de transfer of non-charged species:

i) the transfer of free solvent between POT and solution is governed by $\mathrm{NO}_{3}^{-}$ $\left(K_{\mathrm{NO}_{3}^{-}}^{\prime} \approx K_{\mathrm{H}_{2} \mathrm{O}}^{\prime}\right)$ except at $0.25-0.3 \mathrm{~V}$ where $K_{\mathrm{H}_{2} \mathrm{O}}^{\prime}$ increases quickly $\left(K_{\mathrm{H}_{2} \mathrm{O}}^{\prime}=250-300 \mathrm{~s}^{-1}\right.$ in Figure $6 \mathrm{~b}$ ) in the POT- $\mathrm{NO}_{3}^{-}$film.

ii) between $0.35 \mathrm{~V}$ and $0.2 \mathrm{~V}$ in POT-Cl- films, the electrochemical response, $\Delta q / \Delta E(\omega)$, and the electrogravimetric response, $\Delta m / \Delta E(\omega)$ ), could not be correlated as it was commented above.

iii) from $d \Gamma_{\mathrm{H}_{2} \mathrm{O}}(E) / d \Gamma_{\mathrm{A}^{-}}(E)$ ratios, the evolution of the number of water transferred between the film and the bathing solution per anion can be followed $[93,94]$. Taking into account the molecular volume, one molecule of $\mathrm{NO}_{3}^{-}$or $\mathrm{Cl}^{-}$could replace three water molecules while one molecule of $\mathrm{ClO}_{4}^{-}$about five water molecules. This number is not always an integer number, as predicted by the volume ratio (Figure 7). In a dynamic polymer, the structural changes of POT should have a great influence on these exclusion proportions. In special, about one molecule of water is excluded per anion around $0.3 \mathrm{~V}$ independently of POT film. 


\section{$<$ Figure $7>$}

By integrating the simulated insertion law of Figure 4, the variation of the number of each involved species per surface unit for the three transitions when the polarization potential is decreasing in both $\mathrm{POT}-\mathrm{ClO}_{4}^{-}$and $\mathrm{POT}-\mathrm{NO}_{3}^{-}$films can be observed in Figure 8. At potentials where the species are kinetically faster in both films (about $0.3 \mathrm{~V}$ ), the most of the electroactive sites are protonated owing to the complete $\mathrm{PN} \rightarrow \mathrm{BP}$ transition. Simultaneously, about $90 \%$ of anions are expelled and about $97 \%$ of water molecules are inserted for the $\mathrm{BP} \rightarrow \mathrm{P}$ transition. Therefore, the faster transfer of species takes place when POT has a maximum of polaronic sites perhaps homogeneously distributed together with a little proportion of bipolaronic sites in the polymeric backbone [95].

\section{$<$ Figure $8>$}

That is in agreement with molecular models showing that a fully polaronic form is a serious structural perturbation with respect to the other forms of the polymer $[73,96]$. Consequently, this particular polaronic combination could enhance the transfer of charged species between the film and the solution as the kinetic results ( $K_{i}^{\prime}$ and $\left.G_{i}\right)$ show around $0.3 \mathrm{~V}$ in both films. The smaller anions do not only govern the water transfer because the film could act like a molecular pump. This mechanical movement, which can be controlled by injected charge in the polymeric chain (kinetic control), creates or consumes film free volume where the water can be inserted. This fact is in agreement with the increase of water permeation observed in fully reduced POT films which swell as the acid concentration in the electrolyte solution increases [50]. The increase of anions inside of film excludes water molecules but increases the free volume where the water molecules can be inserted at the same time. In these experimental conditions and polymer structure, the results do not point to non-ideal thermodynamic behavior of free water transfer [91].

\subsection{Approximation to the mechanical expansion/contraction of polymer}

Together with the changes of films thickness promoted by the formation of coil structures around $0.3 \mathrm{~V}$ during the formation of polaronic sites [65], POT films may change the volume to store all species inside the film. From the volume of specie $\left(V_{i}\right)$ transferred during the redox transitions an apparent variation of the film thickness $\left(\Delta d_{f}^{\prime}\right)$ can be calculated as following [97]: 


$$
\Delta d_{f}^{\prime}=N_{A} \sum \delta_{i} \Gamma_{i} V_{i}
$$

where $N_{A}$ is the Avogadro number and $i$ is $\mathrm{A}^{-}, \mathrm{H}_{3} \mathrm{O}^{+}$and $\mathrm{H}_{2} \mathrm{O}$.

Eq (19) can be an indirect estimation of the evolution of the POT film thickness with respect to the applied potentials in $\mathrm{HNO}_{3}$ and $\mathrm{HClO}_{4}$ solutions (Figure 9). The larger size of anions leads to a more swollen film when it is completely oxidized. During the potential perturbation in $a c$ regime, both structural changes due to the insertion/expulsion of species and polymer reconfiguration can affect the transfer of non-charged species. On the contrary, the charged species are only controlled by the electroneutrality achieved inside the film. By resolving the potential-derivative $\Delta d_{f}^{\prime}$, one of the faster changes takes place at $0.3 \mathrm{~V}$ between the $\mathrm{BP} \rightarrow \mathrm{P}$ and $\mathrm{P} \rightarrow \mathrm{LE}$ transition. The second faster change is at $0.5 \mathrm{~V}$ (around $\mathrm{PN} \rightarrow \mathrm{BP}$ transition) and involves the $\mathrm{H}_{3} \mathrm{O}^{+}$ transfer when the most of anions are inserted in the polymer. However, it does not enhance the transfer of free water molecules as $K_{\mathrm{H}_{2} \mathrm{O}}^{\prime}$ results show at these potentials. These results corroborate the mixed mechanism (anion-dynamic polymer) proposed by the transfer of free water.

$<$ Figure $9>$

\section{CONCLUSION}

$a c$-Electrogravimetry has allowed kinetic information to be separated and evaluated for all the transferred species in three different $\mathrm{H}_{2} \mathrm{SO}_{4}$-structured POT films, POT-NO ${ }_{3}^{-}, \mathrm{POT}_{-} \mathrm{ClO}_{4}^{-}$and POT-Cl- films. This information is not easily achieved by traditional analytical techniques. For the same polymeric structure of a POT film, the monoatomic $\mathrm{Cl}^{-}$is exchanged easier and faster than a polyatomic anion with a similar size and mobility $\left(\mathrm{NO}_{3}^{-}\right)$. However, the $\mathrm{ClO}_{4}^{-}$transfer shows different difficulties owing to the big size, geometry and interaction with the polymer structure. Moreover, the features of $\mathrm{ClO}_{4}^{-}$allow the water transfer of POT-ClO ${ }_{4}^{-}$films to be controlled by an exclusion effect at all polarization potentials, or in other words, at all different structures of films (LE, P, BP and PN forms). $\mathrm{In}_{2} \mathrm{SO}_{4}$-structured POT films with smaller dopant anions, it was clearly possible to discuss about a mixed process around $0.3 \mathrm{~V}$ vs SCE, which increases the rate of water transfer: the transfer of anions together with mechanical contractions/expansions of film (both kinetically controlled). At this 
potential, the insertion law points to a polymeric structure formed predominantly by polaron sites. The $\mathrm{H}_{3} \mathrm{O}^{+}$transfer is moderately affected by the anion in solution owing to the chemical protonation/deprotonating reaction, which control this transfer during the $\mathrm{PN} \rightleftarrows \mathrm{BP}$ transitions, even when this cation acts as counter-ion around $0.1 \mathrm{~V}$ in $\mathrm{HClO}_{4}$ solutions during the $\mathrm{LE} \rightleftarrows \mathrm{P}$ transitions.

\section{ACKNOWLEDGMENTS}

Part of this work was supported by CICyT project CTQ2011-28973/BQU. J. A. acknowledges his position to the Generalitat Valenciana.

\section{REFERENCES}

[1] G. Inzelt, M. Pineri, J.W. Schultze, M.A. Vorotyntsev, Electron and proton conducting polymers: recent developments and prospects, Electrochim. Acta. 45 (2000) 2403-2421.

[2] G. Inzelt, Mechanism of Charge Transport in Polymer Modified Electrodes, in: Bard, A. J. (Ed.), Electroanalytical Chemistry, A Series of Advances, Marcel Dekker, Inc., New York, 1993: pp. 89-241.

[3] R.W. Murray, Molecular Design of Electrode Surfaces, Wiley-Blackwell, New York, 1992.

[4] M.E.G. Lyons, Electroactive Polymer Electrochemistry, Part 1: Fundamentals, 1st ed., Springer, New York, 1995.

[5] M.E.G. Lyons, Electroactive Polymer Electrochemistry: Part 2: Methods and Applications, Springer, 1996.

[6] Foster, R. J., Vos, J. G., Theory and Analytical Applications of Modified Electrodes, in: G. Svehla (Ed.), Comprehensive Analytical Chemistry, Elsevier Science Ltd, Amsterdam, 1992: p. 524.

[7] S.R. Forrest, M.E. Thompson, Introduction: Organic Electronics and Optoelectronics, Chem. Rev. 107 (2007) 923-925.

[8] G. Sonmez, Polymeric electrochromics, Chem. Commun. (2005) 5251-5259.

[9] R.J. Mortimer, A.L. Dyer, J.R. Reynolds, Electrochromic organic and polymeric materials for display applications, Displays. 27 (2006) 2-18.

[10] J.M. Bauldreay, M.D. Archer, Dye-modified electrodes for photogalvanic cells, Electrochim. Acta. 28 (1983) 1515-1522.

[11] S. Ashley, Artificial Muscles, Sci. Am. 289 (2003) 52-59.

[12] T.F. Otero, J.M. Sansinena, Bilayer dimensions and movement in artificial muscles, Bioelectrochem. Bioenerg. 42 (1997) 117-122.

[13] Q. Pei, G. Yu, C. Zhang, Y. Yang, A.J. Heeger, Polymer Light-Emitting Electrochemical Cells, Science. 269 (1995) 1086-1088.

[14] L. Edman, Bringing light to solid-state electrolytes: The polymer light-emitting electrochemical cell, Electrochim. Acta. 50 (2005) 3878-3885.

[15] T. Selvaraju, R. Ramaraj, Simultaneous determination of ascorbic acid, dopamine and serotonin at poly(phenosafranine) modified electrode, Electrochem. Commun. 5 (2003) 667-672. 
[16] Y. Wang, S. Hu, A novel nitric oxide biosensor based on electropolymerization poly(toluidine blue) film electrode and its application to nitric oxide released in liver homogenate, Biosens. Bioelectron. 22 (2006) 10-17.

[17] C.M.A. Brett, G. Inzelt, V. Kertesz, Poly(methylene blue) modified electrode sensor for haemoglobin, Anal. Chim. Acta. 385 (1999) 119-123.

[18] A.A. Karyakin, E.E. Karyakina, W. Schuhmann, H.-L. Schmidt, Electropolymerized Azines: Part II. In a Search of the Best Electrocatalyst of NADH Oxidation, Electroanal. 11 (1999) 553-557.

[19] S.-M. Chen, K.-C. Lin, The electrocatalytic properties of polymerized neutral red film modified electrodes, J. Electroanal. Chem. 511 (2001) 101-114.

[20] C.M. Moore, S.D. Minteer, R.S. Martin, Microchip-based ethanol/oxygen biofuel cell, Lab Chip. 5 (2005) 218-225.

[21] N.L. Akers, C.M. Moore, S.D. Minteer, Development of alcohol/O2 biofuel cells using salt-extracted tetrabutylammonium bromide/Nafion membranes to immobilize dehydrogenase enzymes, Electrochim. Acta. 50 (2005) 2521-2525.

[22] K. Yoshikawa, K. Yoshioka, A. Kitani, K. Sasaki, Preparation of highly conducting polyanilines, J. Electroanal. Chem. 270 (1989) 421-427.

[23] J. Yano, M. Kobayashi, S. Yamasaki, Y. Harima, K. Yamashita, Mean redox potentials of polyaniline determined by chronocoulometry, Synth. Met. 119 (2001) 315-316.

[24] A.M. Mohamoud, A.R. Hillman, The effect of anion identity on the viscoelastic properties of polyaniline films during electrochemical film deposition and redox cycling, Electrochim. Acta. 53 (2007) 1206-1216.

[25] C. Weidlich, K.M. Mangold, K. Juttner, EQCM study of the ion exchange behaviour of polypyrrole with different counterions in different electrolytes, Electrochim. Acta. 50 (2005) 1547-1552.

[26] A. Elmansouri, A. Outzourhit, A. Lachkar, N. Hadik, A. Abouelaoualim, M.E. Achour, et al., Influence of the counter ion on the properties of poly(o-toluidine) thin films and their Schottky diodes, Synth. Met. 159 (2009) 292-297.

[27] M. Kalaji, L. Nyholm, L. Peter, A Microelectrode Study of the Influence of Ph and Solution Composition, J. Electroanal. Chem. 313 (1991) 271-289.

[28] G. Zotti, S. Cattarin, N. Comisso, Cyclic Potential Sweep Electropolymerization of Aniline - the Role of Anions in the Polymerization Mechanism, J. Electroanal. Chem. 239 (1988) 387-396.

[29] D. Kumar, Electrochemical and optical behaviour of conducting polymer: poly(otoluidine), Eur. Polym. J. 35 (1999) 1919-1923.

[30] D.D. Borole, U.R. Kapadi, P.P. Kumbhar, D.G. Hundiwale, Influence of inorganic and organic supporting electrolytes on the electrochemical synthesis of polyaniline, poly(o-toluidine) and their copolymer thin films, Mater. Lett. 56 (2002) 685-691.

[31] A. Bund, S. Neudeck, Effect of the solvent and the anion on the doping/dedoping behavior of poly(3,4-ethylenedioxythiophene) films studied with the electrochemical quartz microbalance, J. Phys. Chem. B. 108 (2004) 17845-17850.

[32] W. Plieth, A. Bund, U. Rammelt, S. Neudeck, L.M. Duc, The role of ion and solvent transport during the redox process of conducting polymers, Electrochim. Acta. 51 (2006) 2366-2372.

[33] A. Benyaich, C. Deslouis, T. ElMoustafid, M.M. Musiani, B. Tribollet, Electrochemical properties of PANI films for different counter-ions in acidic $\mathrm{pH}$ analysed by impedance techniques, Electrochim. Acta. 41 (1996) 1781-1785. 
[34] M.C. Gupta, S.S. Umare, Studies on poly(o-methoxyaniline), Macromolecules. 25 (1992) 138-142.

[35] V. Luthra, R. Singh, A. Mansingh, Effect of protonic acids on the dielectric spectroscopy of polyaniline, Synth. Met. 119 (2001) 291-292.

[36] M.J. Henderson, A.R. Hillman, E. Vieil, Ion and solvent transfer discrimination at a poly(o-toluidine) film exposed to $\mathrm{HClO} 4$ by combined electrochemical quartz crystal microbalance (EQCM) and probe beam deflection (PBD), J. Phys. Chem. B. 103 (1999) 8899-8907.

[37] M. J. Henderson, A. Robert Hillman, E. Vieil, A combined electrochemical quartz crystal microbalance (EQCM) and probe beam deflection (PBD) study of a poly(otoluidine) modified electrode in perchloric acid solution, J. Electroanal. Chem. 454 (1998) 1-8.

[38] M.J. Henderson, A.R. Hillman, E. Vieil, Chronoamperometric resolution of ion and solvent transfers at a poly(o-toluidine) modified electrode by combined electrochemical quartz crystal microbalance (EQCM) and probe beam deflection (PBD), Electrochim. Acta. 45 (2000) 3885-3894.

[39] C. Gabrielli, H. Perrot, A. Rubin, M.C. Pham, B. Piro, Ac-electrogravimetry study of ionic exchanges on a polypyrrole modified electrode in various electrolytes, Electrochem. Commun. 9 (2007) 2196-2201.

[40] A. Rubin, H. Perrot, C. Gabrielli, M.C. Pham, B. Piro, Electrochemical and electrogravimetric behaviors of conducting polymer. Theoretical aspects and application to co-polymer films based on juglone, Electrochim. Acta. 55 (2010) 6136-6146.

[41] L.T.T. Kim, O. Sel, C. Debiemme-Chouvy, C. Gabrielli, C. Laberty-Robert, H. Perrot, et al., Proton transport properties in hybrid membranes investigated by acelectrogravimetry, Electrochem. Commun. 12 (2010) 1136-1139.

[42] J. Agrisuelas, C. Gabrielli, J.J. Garcia-Jareño, H. Perrot, F. Vicente, Ionic and Free Solvent Motion in Poly(azure A) Studied by ac-Electrogravimetry, J. Phys. Chem. C. 115 (2011) 11132-11139.

[43] C. Gabrielli, M. Keddam, N. Nadi, H. Perrot, Ions and solvent transport across conducting polymers investigated by ac electrogravimetry. Application to polyaniline, J. Electroanal. Chem. 485 (2000) 101-113.

[44] Y. Lee, C. Chang, S. Yau, L. Fan, Y. Yang, L.O. Yang, et al., Conformations of Polyaniline Molecules Adsorbed on Au(111) Probed by in Situ STM and ex Situ XPS and NEXAFS, J. Am. Chem. Soc. 131 (2009) 6468-6474.

[45] J. Agrisuelas, C. Gabrielli, J.J. García-Jareño, H. Perrot, F. Vicente, Kinetic and Mechanistic Aspects of a Poly(o-Toluidine)-Modified Gold Electrode. 2. Alternating Current Electrogravimetry Study in H2SO4 Solutions, J. Phys. Chem. C. 116 (2012) 15630-15640.

[46] V. Bavastrello, S. Carrara, M.K. Ram, C. Nicolini, Optical and Electrochemical Properties of Poly(o-toluidine) Multiwalled Carbon Nanotubes Composite Langmuir-Schaefer Films, Langmuir. 20 (2004) 969-973.

[47] Y.Z. Wang, J. Joo, C.-H. Hsu, J.P. Pouget, A.J. Epstein, Charge Transport of Hydrochloric Acid Doped Polyaniline and Poly(o-toluidine) Fibers: Role of Processing, Macromolecules. 27 (1994) 5871-5876.

[48] P. Ocon, L. Vazquez, R.C. Salvarezza, A.J. Arvia, P. Herrasti, J.M. Vara, Scanning Tunneling Microscopy Fractal Characterization of Poly(o-toluidine) Films Produced Electrochemically on Polyfaceted Gold Single Crystal Spheres, J. Phys. Chem. 98 (1994) 2418-2425. 
[49] J.A. Osaheni, S.A. Jenekhe, H. Vanherzeele, J.S. Meth, Third-order nonlinear optical properties of thin films of polyanilines and poly(o-toluidines), Chem. Mater. 3 (1991) 218-221.

[50] A.R. Hillman, L. Bailey, A. Glidle, J.M. Cooper, N. Gadegaard, J.R.P. Webster, Spatial distributions of polymer and mobile species in poly(o-toluidine) films, J. Electroanal. Chem. 532 (2002) 269-276.

[51] Q. Yang, Y. Zhang, H. Li, Y. Zhang, M. Liu, J. Luo, et al., Electrochemical copolymerization study of o-toluidine and o-aminophenol by the simultaneous EQCM and in situ FTIR spectroelectrochemisty, Talanta. 81 (2010) 664-672.

[52] S. Bilal, A.-H.A. Shah, R. Holze, A correlation of electrochemical and spectroelectrochemical properties of poly(o-toluidine), Electrochim. Acta. 54 (2009) 4851-4856.

[53] M. Jozefowicz, A. Epstein, J. Pouget, J. Masters, A. Ray, A. Macdiarmid, X-Ray Structure of the Polyaniline Derivative Poly(ortho-Toluidine) - the Structural Origin of Charge Localization, Macromolecules. 24 (1991) 5863-5866.

[54] Z. Wang, A. Ray, A. Macdiarmid, A. Epstein, Electron Localization and Charge Transport in Poly(o-Toluidine) - a Model Polyaniline Derivative, Phys. Rev. B. 43 (1991) 4373-4384.

[55] C. Gabrielli, J.J. Garcia-Jareño, H. Perrot, Charge compensation process in polypyrrole studied by ac electrogravimetry, Electrochim. Acta. 46 (2001) 40954103.

[56] C. Gabrielli, J.J. García-Jareño, M. Keddam, H. Perrot, F. Vicente, AcElectrogravimetry Study of Electroactive Thin Films. I. Application to Prussian Blue, J. Phys. Chem. B. 106 (2002) 3182-3191.

[57] C. Gabrielli, H. Perrot, Modeling and Numerical Simulations II, in: Schlesinger, M. (Ed.), In Modern Aspects of Electrochemistry, Springer, New York, 2009: p. $151-238$.

[58] J.J. Garcia-Jareño, A. Sanmatias, F. Vicente, C. Gabrielli, M. Keddam, H. Perrot, Study of Prussian Blue (PB) films by ac-electrogravimetry: influence of, Electrochim. Acta. 45 (2000) 3765-3776.

[59] J.J. García-Jareño, D. Giménez-Romero, F. Vicente, C. Gabrielli, M. Keddam, H. Perrot, EIS and Ac-Electrogravimetry Study of PB Films in $\mathrm{KCl}, \mathrm{NaCl}$, and $\mathrm{CsCl}$ Aqueous Solutions, J. Phys. Chem. B. 107 (2003) 11321-11330.

[60] A.R. Hillman, S.J. Daisley, S. Bruckenstein, Ion and solvent transfers and trapping phenomena during n-doping of PEDOT films, Electrochim. Acta. 53 (2008) 3763-3771.

[61] C. Gabrielli, J.J. Garcia-Jareño, M. Keddam, H. Perrot, F. Vicente, AcElectrogravimetry Study of Electroactive Thin Films. II. Application to Polypyrrole, J. Phys. Chem. B. 106 (2002) 3192-3201.

[62] C. Gabrielli, J. Garcia-Jareño, H. Perrot, Charge transport in electroactive thin films investigated by ac electragravimetry, ACH-Models Chem. 137 (2000) 269297.

[63] J. Agrisuelas, J.J. Garcia-Jareño, D. Gimenez-Romero, F. Vicente, Innovative Combination of Three Alternating Current Relaxation Techniques: Electrical Charge, Mass, and Color Impedance Spectroscopy. Part I: The Tool, J. Phys. Chem. C. 113 (2009) 8430-8437.

[64] J. Agrisuelas, C. Gabrielli, J.J. García-Jareño, H. Perrot, F. Vicente, Kinetic and Mechanistic Aspects of a Poly(o-toluidine)-Modified Gold Electrode. 1. Simultaneous Cyclic Spectroelectrochemistry and Electrogravimetry Studies in H2SO4 Solutions, J. Phys. Chem. C. 116 (2012) 15620-15629. 
[65] J. Agrisuelas, C. Gabrielli, J. J. García-Jareño, H. Perrot, F. Vicente, Effects of anions size on the redox behavior of poly(o-toluidine) in acid solutions. An in situ vis-NIR cyclic spectroelectrogravimetry study, Electrochim. Acta. 125 (2014) 8393.

[66] D. Orata, D. Buttry, Determination of Ion Populations and Solvent Content as Functions of Redox State and Ph in Polyaniline, J. Am. Chem. Soc. 109 (1987) 3574-3581.

[67] H.N. Dinh, V.I. Birss, Characteristics of the polyaniline anodic pre-peak, Electrochim. Acta. 44 (1999) 4763-4771.

[68] X. Yang, Q. Xie, S. Yao, A comparative study on polyaniline degradation by an electrochemical quartz crystal impedance system: electrode and solution effects, Synth. Met. 143 (2004) 119-128.

[69] J. Lopez-Palacios, E. Munoz, M. Aranzazu Heras, A. Colina, V. Ruiz, Study of polyaniline films degradation by thin-layer bidimensional spectroelectrochemistry, Electrochim. Acta. 52 (2006) 234-239.

[70] Z. Yang, D.H. Coutinho, R. Sulfstede, K.J. Balkus, J.R. Ferraris, Proton conductivity of acid-doped meta-polyaniline, J. Membr. Sci. 313 (2008) 86-90.

[71] J. Agrisuelas, C. Gabrielli, J.J. Garcia-Jareño, D. Gimenez-Romero, H. Perrot, F. Vicente, Spectroelectrochemical identification of the active sites for protons and anions insertions into poly-(Azure a) thin polymer films, J. Phys. Chem. C. 111 (2007) 14230-14237.

[72] K. Lee, A. Heeger, Y. Cao, Reflectance Spectra of Polyaniline, Synth. Met. 72 (1995) 25-34.

[73] J.N. Petrova, J.R. Romanova, G.K. Madjarova, A.N. Ivanova, A.V. Tadjer, Fully Doped Oligomers of Emeraldine Salt: Polaronic versus Bipolaronic Configuration, J. Phys. Chem. B. 115 (2011) 3765-3776.

[74] M.C. Bernard, A. Hugot-Le Goff, Quantitative characterization of polyaniline films using Raman spectroscopy I: Polaron lattice and bipolaron, Electrochim. Acta. 52 (2006) 595-603.

[75] L.T.T. Kim, C. Gabrielli, A. Pailleret, H. Perrot, Correlation between ionexchange properties and swelling/shrinking processes in hexasulfonated calix[6]arene doped polypyrrole films: ac-electrogravimetry and electrochemical atomic force microscopy investigations, Electrochim. Acta. 56 (2011) 3516-3525.

[76] L.T.T. Kim, C. Gabrielli, A. Pailleret, H. Perrot, Ions/Solvent Exchanges and Electromechanical Processes in Hexasulfonated Calix[6]Arene Doped Polypyrrole Films: Towards a Relaxation Mechanism, Electrochem. Solid State Lett. 14 (2011) F9-F11.

[77] L. Lizarraga, E.M. Andrade, M.I. Florit, F.V. Molina, Quasi-Equilibrium Volume Changes of Polyaniline Films upon Redox Switching. Formal Potential Distribution and Configurational Modeling, J. Phys. Chem. B. 109 (2005) 1881518821.

[78] K. Kaneto, M. Kaneko, Contribution of conformational change of polymer structure to electrochemomechanical deformation based on polyaniline, Appl. Biochem. Biotechnol. 96 (2001) 13-23.

[79] L. Lizarraga, E.M. Andrade, F.V. Molina, Anion exchange influence on the electrochemomechanical properties of polyaniline, Electrochim. Acta. 53 (2007) $538-548$.

[80] J. Agrisuelas, J.J. García-Jareño, D. Gimenez-Romero, F. Vicente, An approach to the electrochemical activity of poly-(phenothiazines) by complementary 
electrochemical impedance spectroscopy and Vis-NIR spectroscopy, Electrochim. Acta. 55 (2010) 6128-6135.

[81] J. Agrisuelas, C. Gabrielli, J.J. García-Jareño, H. Perrot, F. Vicente, Effects of anions size on the redox behavior of poly(o-toluidine) in acid solutions. An in situ vis-NIR cyclic spectroelectrogravimetry study., Submitted. (2013).

[82] Y. Zhang, P.S. Cremer, Interactions between macromolecules and ions: the Hofmeister series, Curr. Opin. Chem. Biol. 10 (2006) 658-663.

[83] H.S. Kolla, S.P. Surwade, X.Y. Zhang, A.G. MacDiarmid, S.K. Manohar, Absolute molecular weight of polyaniline, J. Am. Chem. Soc. 127 (2005) 1677016771.

[84] Q. Zhang, A. Khajo, T. Sai, I. de Albuquerque, R.S. Magliozzo, K. Levon, Intramolecular Transport of Charge Carriers in Trimeric Aniline upon a ThreeStep Acid Doping process, J. Phys. Chem. A. 116 (2012) 7629-7635.

[85] F. Vicente, M.A. Núñez-Flores, C. Sanz, Kalousek polarographic study of paludrine and chlorhexidine hydrochlorides, Electrochim. Acta. 30 (1985) 17231725.

[86] A.N. Frumkin, B.B. Damaskin, Adsorption of organic compounds at electrodes, in: B.E. Conway (Ed.), Modern Aspects of Electrochemistry, Butterworth, London, 1964: pp. 149-223.

[87] E. Laviron, The use of linear potential sweep voltammetry and of a.c. voltammetry for the study of the surface electrochemical reaction of strongly adsorbed systems and of redox modified electrodes, J. Electroanal. Chem. 100 (1979) 263-270.

[88] Allen J. Bard, Larry R. Faulkner, Electrochemical Methods: Fundamentals and Applications, 2nd Edition, Wiley-Blackwell, New York, 2001.

[89] J. Redepenning, B. Miller, S. Burnham, Reversible Voltammetric Response of Electrodes Coated with Permselective Redox Films, Anal. Chem. 66 (1994) 15601565.

[90] D. Benito, C. Gabrielli, J.J. García-Jareño, M. Keddam, H. Perrot, F. Vicente, An electrochemical impedance and ac-electrogravimetry study of PNR films in aqueous salt media, Electrochem. Commun. 4 (2002) 613-619.

[91] A.R. Hillman, M.A. Mohamoud, Ion, solvent and polymer dynamics in polyaniline conducting polymer films, Electrochim. Acta. 51 (2006) 6018-6024.

[92] A.R. Hillman, M.A. Mohamoud, S. Bruckenstein, Modelling mobile species dynamics within electroactive films under mixed thermodynamic and kinetic control, Electroanal. 17 (2005) 1421-1432.

[93] I. Jureviciute, S. Bruckenstein, A.R. Hillman, Counter-ion specific effects on charge and solvent trapping in poly(vinylferrocene) films, J. Electroanal. Chem. 488 (2000) 73-81.

[94] I. Jureviciute, S. Bruckenstein, A.R. Hillman, A. Jackson, Kinetics of redox switching of electroactive polymers using the electrochemical quartz crystal microbalance. Part I. Identifying the rate limiting step in the presence of coupled electron/ion and solvent transfer, Phys. Chem. Chem. Phys. 2 (2000) 4193-4198.

[95] K. Aoki, Y. Teragishi, A fractal feature of the conducting zone by conversion rates from any redox state into the fully conducting state of polyaniline films, J. Electroanal. Chem. 441 (1998) 25-31.

[96] W.S. Huang, A.G. Macdiarmid, Optical-Properties of Polyaniline, Polymer. 34 (1993) 1833-1845. 
[97] D. Giménez-Romero, P.R. Bueno, C. Gabrielli, C. Castaño, H. Perrot, J.J. GarcíaJareño, et al., Mass/charge balance as a tool to estimate dimensional change in polypyrrole-based actuators, Electrochem. Commun. 8 (2006) 195-199. 


\section{TABLES}

Table 1. Values of the parameters $R_{p}$ and $C_{p}$ for the parallel reaction obtained for the fitting of the experimental data with eq (16).

\begin{tabular}{|c|c|c|c|c|c|c|}
\hline \multirow[b]{2}{*}{$\begin{array}{l}\boldsymbol{E} \\
\mathbf{V}\end{array}$} & \multicolumn{2}{|c|}{$\mathrm{HNO}_{3}$} & \multicolumn{2}{|c|}{$\mathrm{HClO}_{4}$} & \multicolumn{2}{|c|}{$\mathrm{HCl}$} \\
\hline & $\begin{array}{c}R_{p} \\
\mathrm{k} \Omega \mathbf{c m}^{2}\end{array}$ & $\begin{array}{c}C_{p} \\
\mathrm{mF} \mathbf{c m}^{-2}\end{array}$ & $\begin{array}{c}R_{p} \\
\mathrm{k} \Omega \mathrm{cm}^{2}\end{array}$ & $\begin{array}{c}C_{p} \\
\mathrm{mF} \mathrm{cm}\end{array}$ & $\begin{array}{c}R_{p} \\
\mathrm{k} \Omega \mathrm{cm}^{2}\end{array}$ & $\begin{array}{c}C_{p} \\
\mathrm{mF} \mathbf{c m}^{-2}\end{array}$ \\
\hline 0.40 & - & - & 14.0 & 7 & - & - \\
\hline 0.35 & - & - & 17.0 & 5 & - & - \\
\hline 0.30 & 1.0 & 0.8 & 18.2 & 2 & - & - \\
\hline 0.25 & 1.3 & 0.8 & 22.3 & 2 & - & - \\
\hline 0.20 & 6.7 & 1 & 16.1 & 1 & - & - \\
\hline 0.15 & 8.8 & 2 & 10.4 & 11 & 14.8 & 3 \\
\hline 0.10 & 7.5 & 37 & 5.4 & 17 & 10.6 & 9 \\
\hline 0.05 & 6.5 & 155 & 4.2 & 47 & 8.2 & 121 \\
\hline
\end{tabular}


Table 2. Parameters used in the simulated curves of $d \Gamma_{i}(E) / d E$ in eq (18) from the data of Figure 4 for the POT- $\mathrm{NO}_{3}^{-}$film. $\mathrm{PN} \rightarrow \mathrm{BP}$ is the pernigraniline-bipolaron transition, $\mathrm{BP} \rightarrow \mathrm{P}$, the bipolaron-polaron transition and $\mathrm{P} \rightarrow \mathrm{LE}$, the polaron-leucoemeraldine transition.

\begin{tabular}{lccccc}
\hline Transition process & $\mathbf{P N} \rightarrow \mathbf{B P}$ & \multicolumn{2}{c}{$\mathbf{B P} \rightarrow \mathbf{P}$} & \multicolumn{2}{c}{$\mathbf{P} \rightarrow \mathbf{L E}$} \\
\hline \multicolumn{1}{c}{ Specie $i$} & $\mathrm{H}_{3} \mathrm{O}^{+}$ & $\mathrm{NO}_{3}^{-}$ & $\mathrm{H}_{2} \mathrm{O}$ & $\mathrm{NO}_{3}^{-}$ & $\mathrm{H}_{2} \mathrm{O}$ \\
\hline$\Gamma_{i}^{\text {max }} / \mathrm{nmol} \mathrm{cm}^{-2}$ & 19 & 46 & 118 & 28 & 53 \\
$b_{i}-b_{i}^{\prime} / \mathrm{V}^{-1}$ & 16 & 16 & 21 & 14 & 17 \\
$E_{p, i} / \mathrm{V}$ & 0.554 & 0.429 & 0.440 & 0.115 & 0.103 \\
\hline
\end{tabular}


Table 3. Parameters used in the simulated curves of $d \Gamma_{i}(E) / d E$ in eq (18) from the data of Figure 4 for the POT- $\mathrm{ClO}_{4}^{-}$film. $\mathrm{PN} \rightarrow \mathrm{BP}$ is the pernigraniline-bipolaron transition, $\mathrm{BP} \rightarrow \mathrm{P}$, the bipolaron-polaron transition and $\mathrm{P} \rightarrow \mathrm{LE}$, the polaron-leucoemeraldine transition.

\begin{tabular}{lcccccc}
\hline Transition process & $\mathbf{P N} \rightarrow \mathbf{B P}$ & \multicolumn{2}{c}{$\mathbf{B P} \rightarrow \mathbf{P}$} & \multicolumn{3}{c}{$\mathbf{P} \rightarrow \mathbf{L E}$} \\
\hline \multicolumn{1}{c}{ Specie $i$} & $\mathrm{H}_{3} \mathrm{O}^{+}$ & $\mathrm{ClO}_{4}^{-}$ & $\mathrm{H}_{2} \mathrm{O}$ & $\mathrm{ClO}_{4}^{-}$ & $\mathrm{H}_{3} \mathrm{O}^{+}$ & $\mathrm{H}_{2} \mathrm{O}$ \\
\hline$\Gamma_{i}^{\text {max }} / \mathrm{nmol} \mathrm{cm}^{-2}$ & 25 & 31 & 111 & 25 & 4 & 59 \\
$b_{i}-b_{i}^{\prime} / \mathrm{V}^{-1}$ & 17 & 14 & 22 & 12 & 23 & 17 \\
$E_{p, i} / \mathrm{V}$ & 0.437 & 0.481 & 0.497 & 0.122 & 0.101 & 0.096 \\
\hline
\end{tabular}




\section{FIGURES CAPTIONS}

Figure 1. Cyclic voltammogram (a) and mass response (b) obtained with a $100 \mathrm{mV} \mathrm{s}^{-1}$ potential scan rate of a gold electrode modified by POT- $\mathrm{NO}_{3}^{-}$, POT- $\mathrm{ClO}_{4}^{-}$or POT-Cl ${ }^{-}$ film. Open symbols indicate the oxidation direction and filled symbols the reduction direction.

Figure 2. Charge/potential transfer function (a, c and e), $\Delta q / \Delta E(\omega)$, and electrogravimetric transfer function ( $\mathrm{b}, \mathrm{d}$ and $\mathrm{f}), \Delta m / \Delta E(\omega)$, at different polarization potentials of a gold electrode modified by POT- $\mathrm{NO}_{3}^{-}$(a and b), POT-ClO ${ }_{4}^{-}$(c and d) or POT- $\mathrm{Cl}^{-}$(e and f) film. The continuous lines are the theoretical curves calculated from eq (16) and (17).

Figure 3. Mass/charge transfer function at low frequency, $F \Delta m / \Delta q(L F)$, on potential scale of a gold electrode modified by POT- $\mathrm{NO}_{3}^{-}$, POT- $\mathrm{ClO}_{4}^{-}$or POT-Cl- film.

Figure 4. Changes of the derivative of the insertion law with respect to the potential, $d \Gamma_{i}(E) / d E$, at different polarization potentials of a gold electrode modified by POT$\mathrm{NO}_{3}^{-}$(a) or POT-ClO ${ }_{4}^{-}$film (b) obtained by fitting $\Delta q / \Delta E(\omega)$ and $\Delta m / \Delta E(\omega)$ with the theoretical functions, eq (16) and (17), respectively. The continuous lines are the simulated curves of $d \Gamma_{i}(E) / d E$, eq (18), using the parameters in Table 2 and Table 3. $\mathrm{PN} \rightarrow \mathrm{BP}$ is the pernigraniline-bipolaron transition, $\mathrm{BP} \rightarrow \mathrm{P}$, the bipolaron-polaron transition and $\mathrm{P} \rightarrow \mathrm{LE}$, the polaron-leucoemeraldine transition.

Figure 5. Change of the kinetic parameters, $G_{\mathrm{NO}_{3}^{-}}, G_{\mathrm{ClO}_{4}^{-}}$and $G_{\mathrm{Cl}^{-}}(\mathrm{a}), G_{\mathrm{H}_{2} \mathrm{O}}$ (b) and $G_{\mathrm{H}_{3} \mathrm{O}^{+}}$ (c) on potential scale of a gold electrode modified by POT- $\mathrm{NO}_{3}^{-}$, POT- $\mathrm{ClO}_{4}^{-}$or POT-Clfilm obtained by fitting $\Delta q / \Delta E(\omega)$ and $\Delta m / \Delta E(\omega)$ with the theoretical functions, eq (16) and (17), respectively.

Figure 6. Change of the kinetic parameters, $K_{\mathrm{NO}_{3}^{-}}^{\prime}, K_{\mathrm{ClO}_{4}^{-}}^{\prime}$ and $K_{\mathrm{Cl}^{-}}^{\prime}(\mathrm{a}), K_{\mathrm{H}_{2} \mathrm{O}}^{\prime}(\mathrm{b})$ and $K_{\mathrm{H}_{3} \mathrm{O}^{+}}^{\prime}$ (c) on potential scale of a gold electrode modified by POT- $\mathrm{NO}_{3}^{-}$, POT- $\mathrm{ClO}_{4}^{-}$or POT-Cl${ }^{-}$ 
film obtained by fitting $\Delta q / \Delta E(\omega)$ and $\Delta m / \Delta E(\omega)$ with the theoretical functions, eq (16) and (17), respectively.

Figure 7. Predicted variation of the ratio $d \Gamma_{\mathrm{H}_{2} \mathrm{O}}(E) / d \Gamma_{\mathrm{A}^{-}}(E)$ on potential scale as an estimation of the number of water molecules which is associated with the transfer of $\mathrm{A}^{-}=\mathrm{NO}_{3}^{-}, \mathrm{ClO}_{4}^{-}$or $\mathrm{Cl}^{-}$of a gold electrode modified by POT- $\mathrm{NO}_{3}^{-}$, POT- $\mathrm{ClO}_{4}^{-}$or POT$\mathrm{Cl}^{-}$film respectively obtained by the corresponding simulated curves of $d \Gamma_{i}(E) / d E$, eq (18).

Figure 8. Predicted variation of the global insertion law by integration of the simulated partial curves of $d \Gamma_{i}(E) / d E$ for all the involved species on potential scale of a gold electrode modified by POT- $\mathrm{NO}_{3}^{-}$(a) or POT-ClO- film (b) obtained by fitting $\Delta q / \Delta E(\omega)$ and $\Delta m / \Delta E(\omega)$ with the theoretical functions, eq (16) and (17), respectively. $\mathrm{PN} \rightarrow \mathrm{BP}$ is the pernigraniline-bipolaron transition, $\mathrm{BP} \rightarrow \mathrm{P}$, the bipolaronpolaron transition and $\mathrm{P} \rightarrow \mathrm{LE}$, the polaron-leucoemeraldine transition.

Figure 9. Predicted variation of the relative thickness $\Delta d_{f}^{\prime}$ of a gold electrode modified by $\mathrm{POT}-\mathrm{NO}_{3}^{-}$or $\mathrm{POT}_{-} \mathrm{ClO}_{4}^{-}$film from eq (19) on potential scale (a) and the corresponding potential-derivative $\Delta d_{f}^{\prime}(\mathrm{b})$. 


\section{FIGURES}

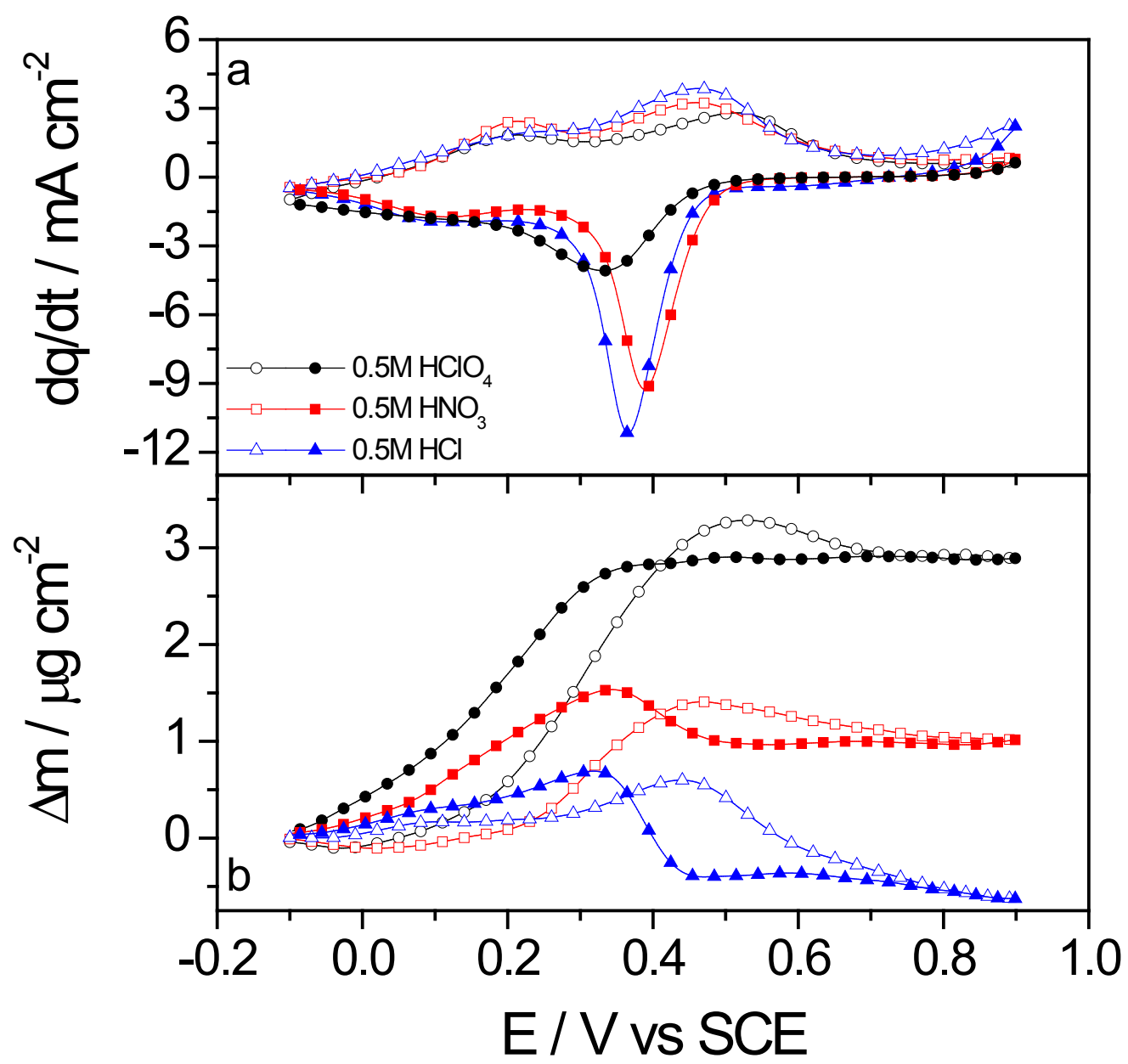

Figure 1 


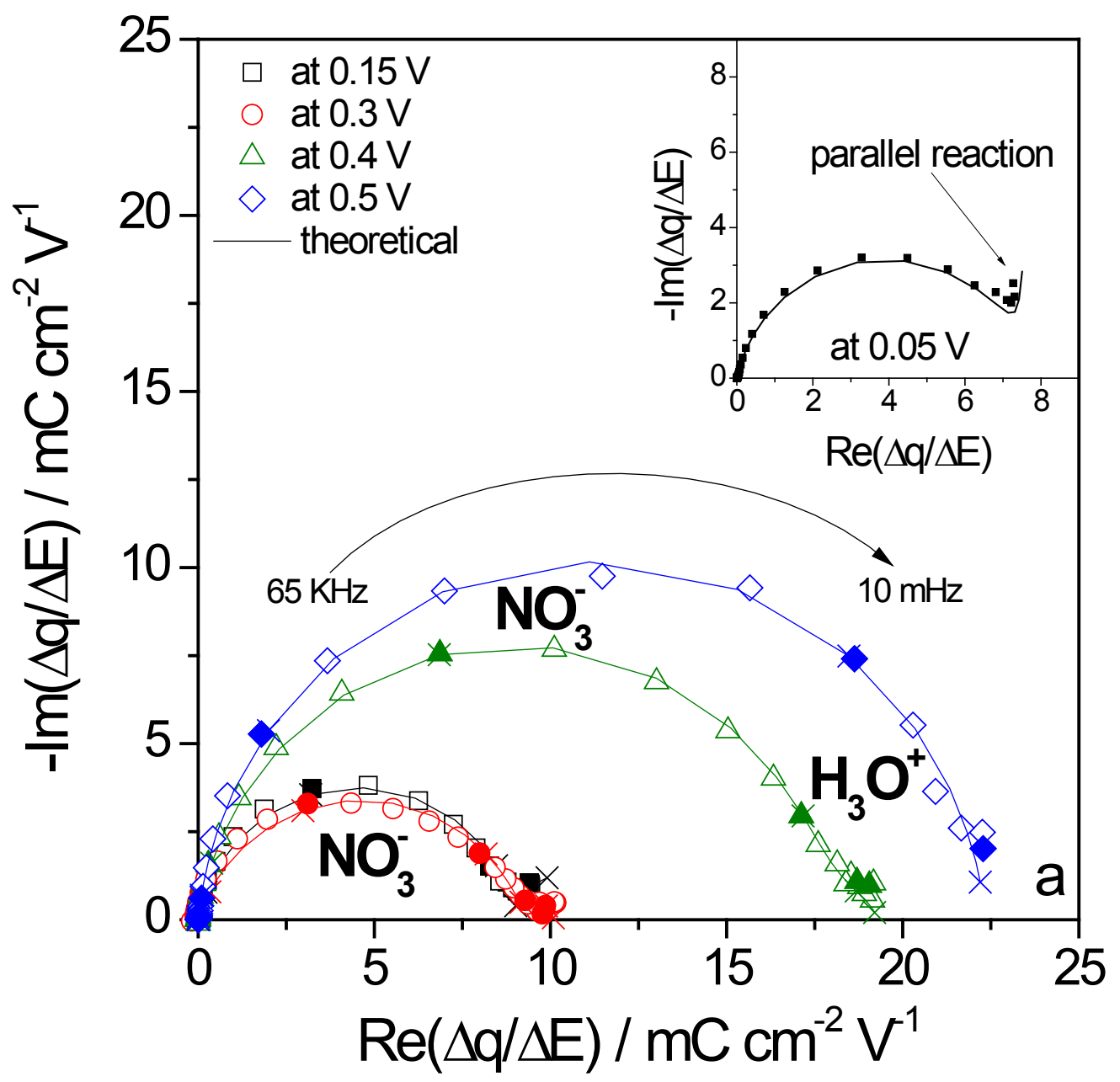

Figure $2 \mathrm{a}$ 


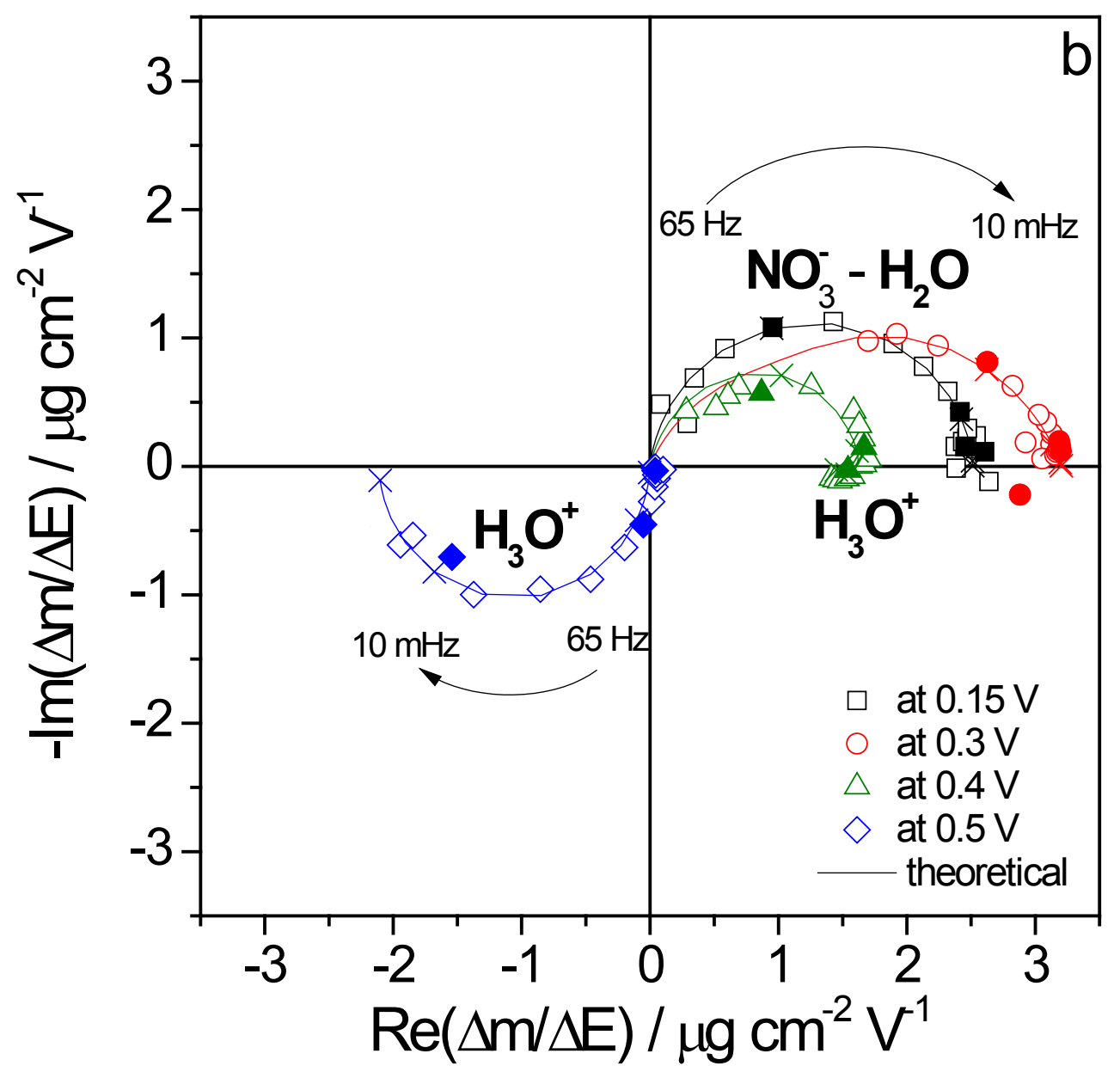

Figure $2 b$ 


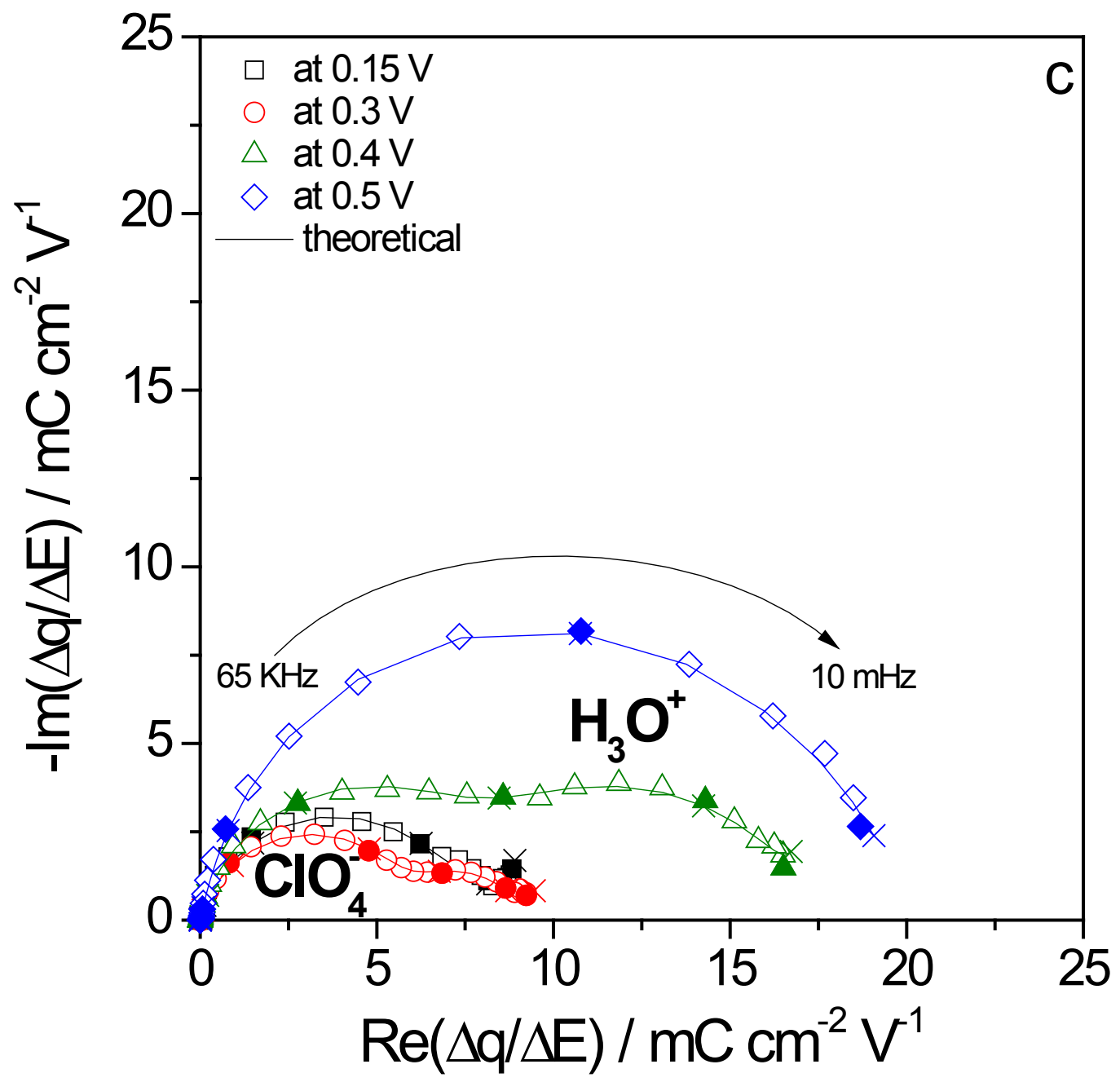

Figure 2c 


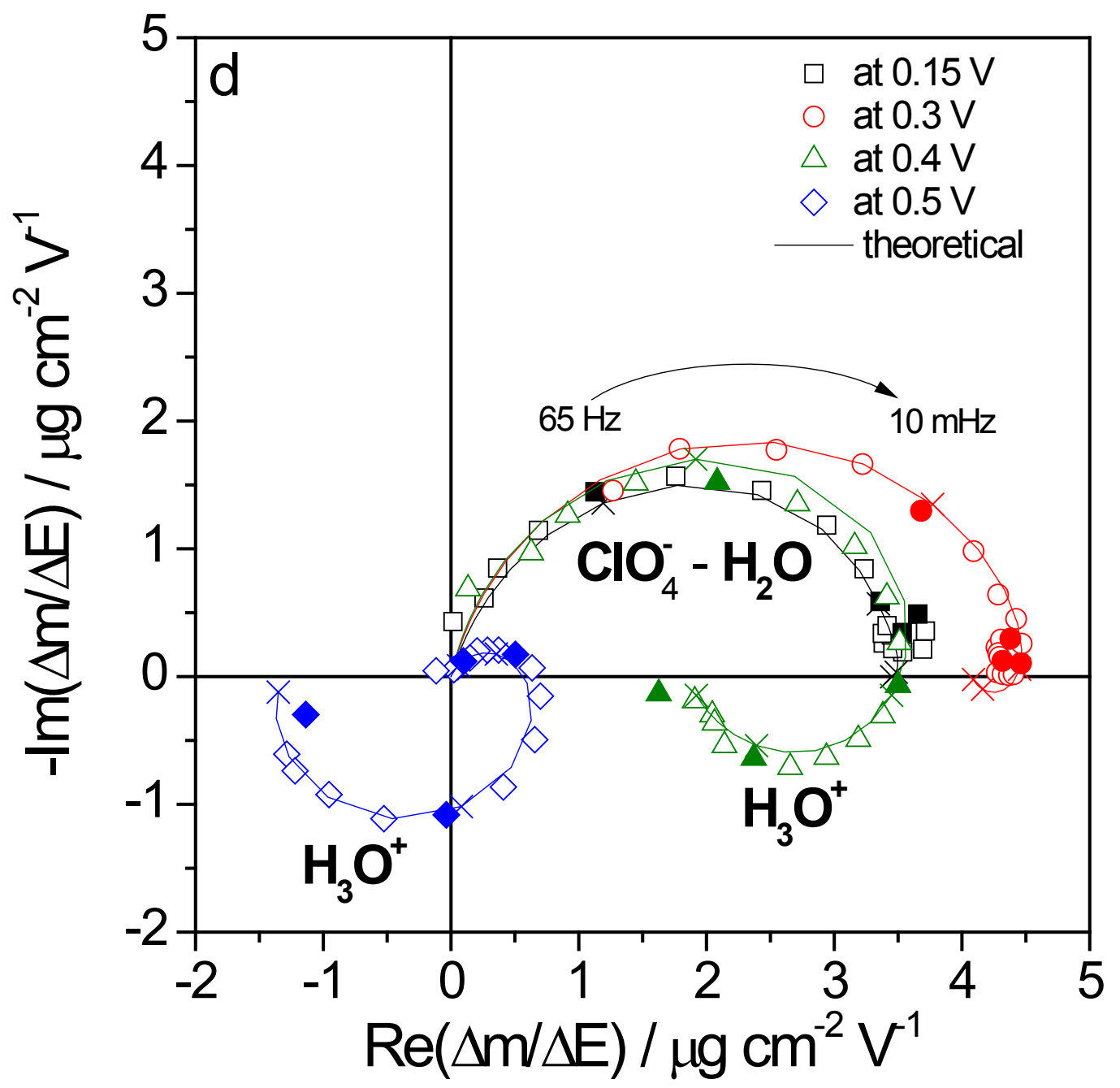

Figure 2d 


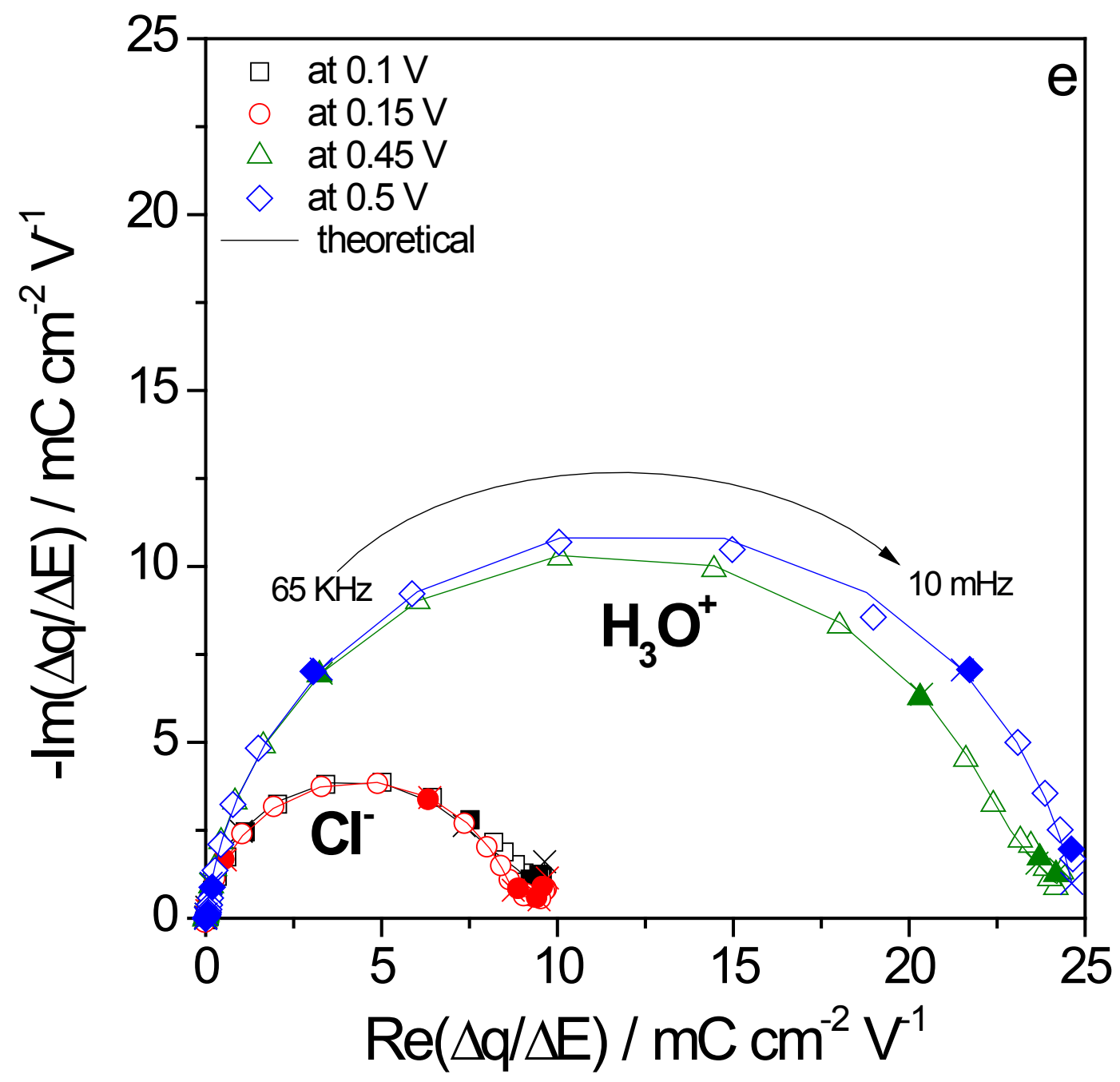

Figure 2e 


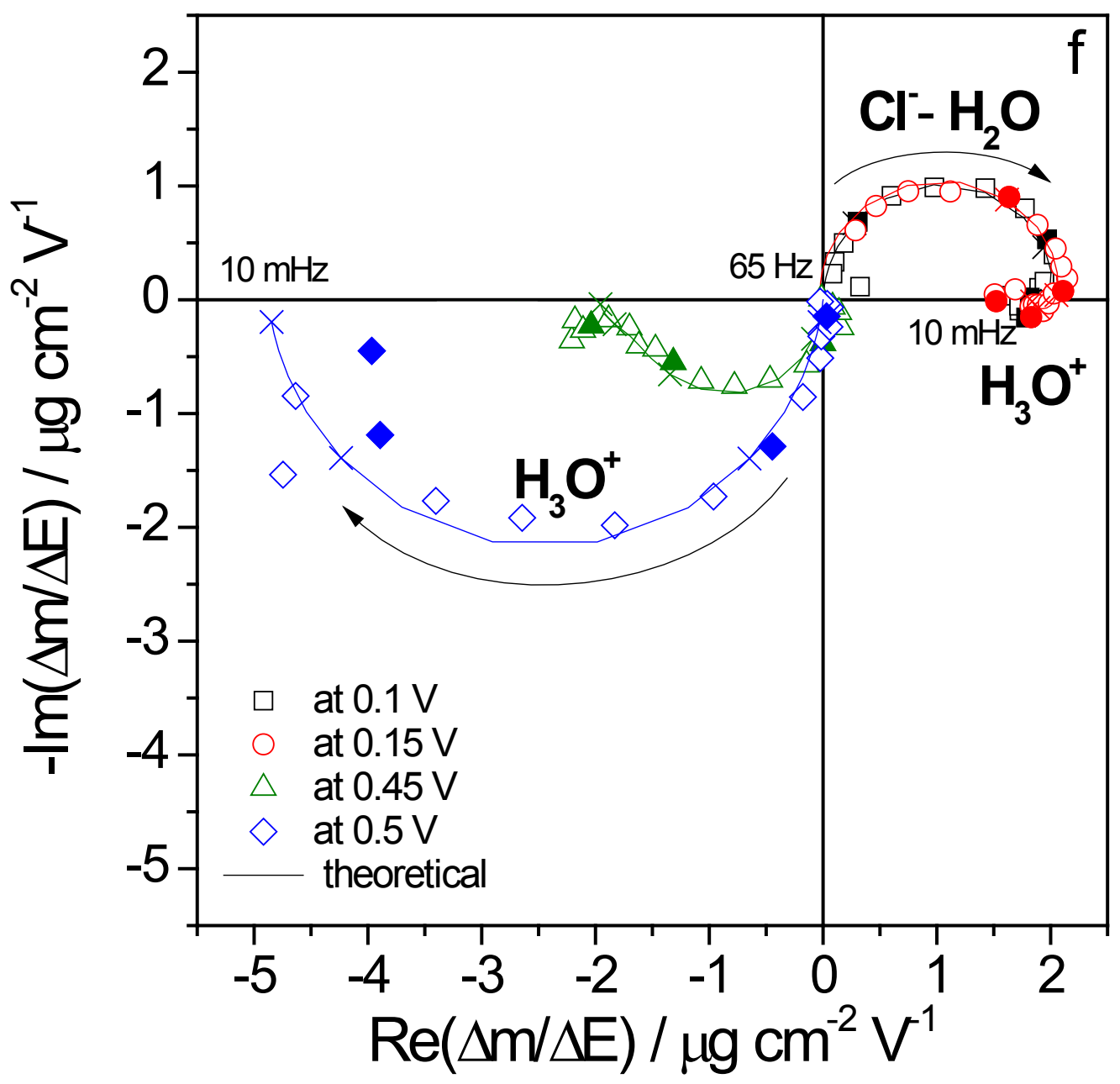

Figure $2 \mathrm{f}$ 


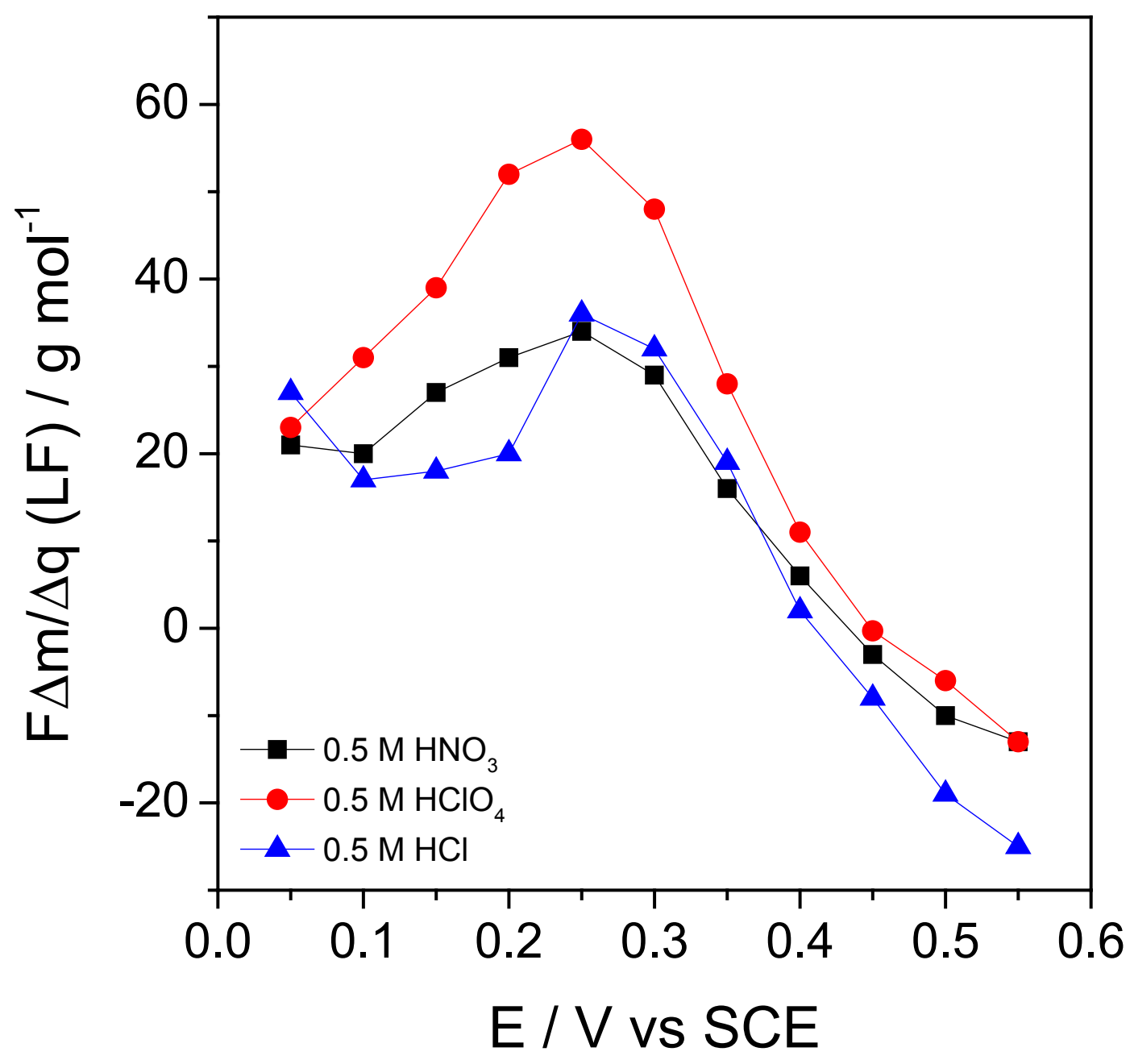

Figure 3 


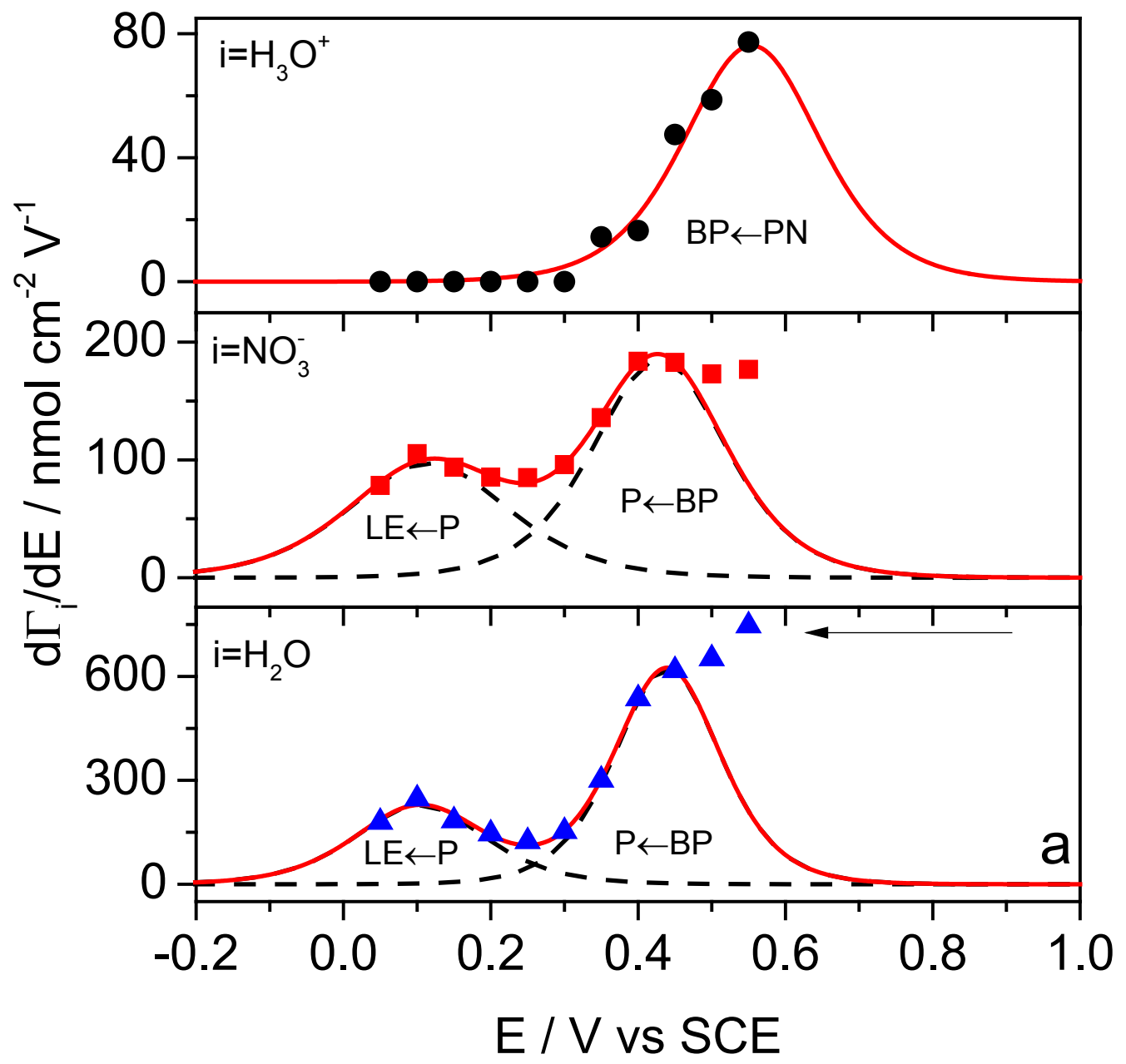

Figure $4 \mathrm{a}$ 


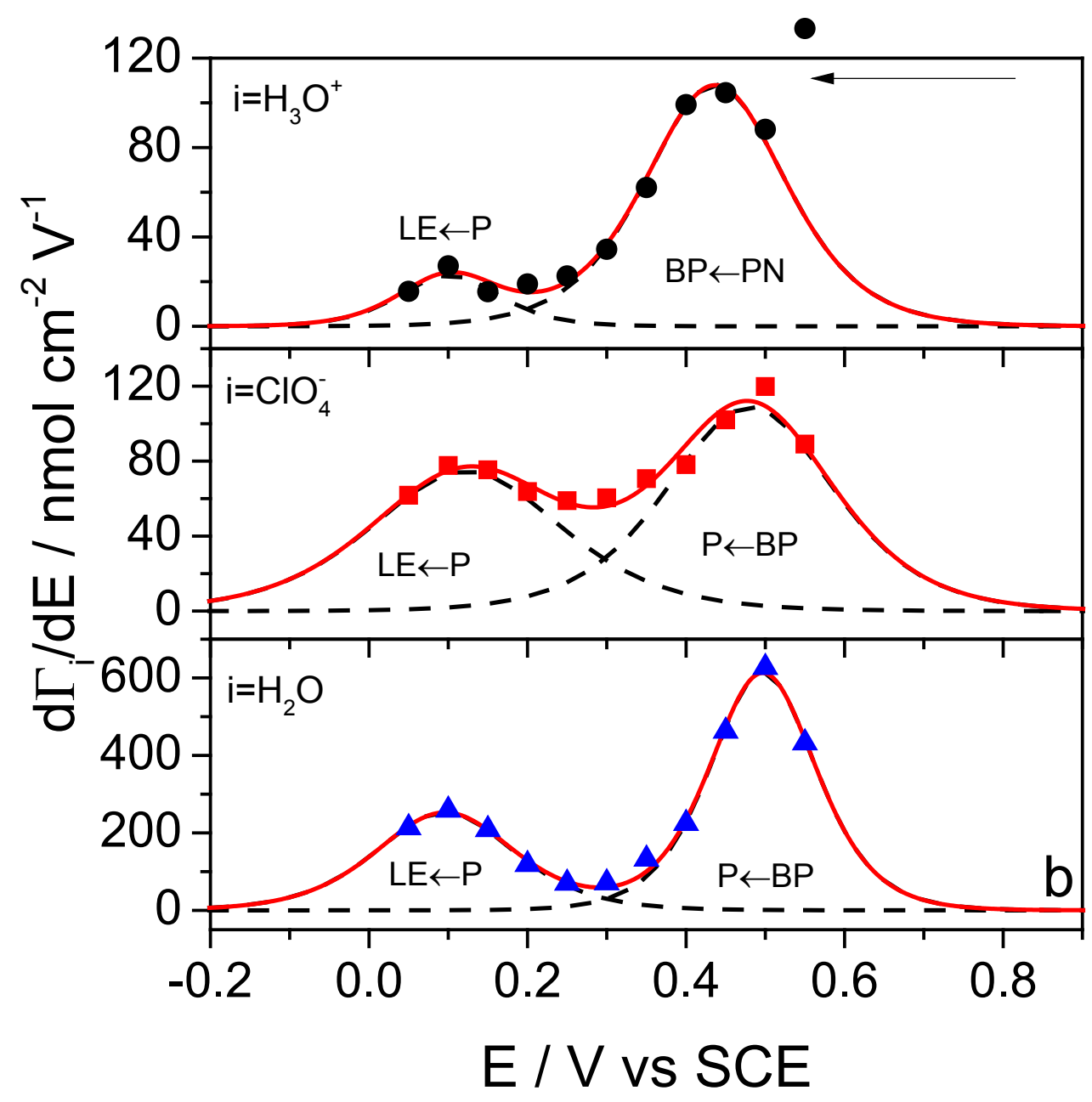

Figure $4 b$ 


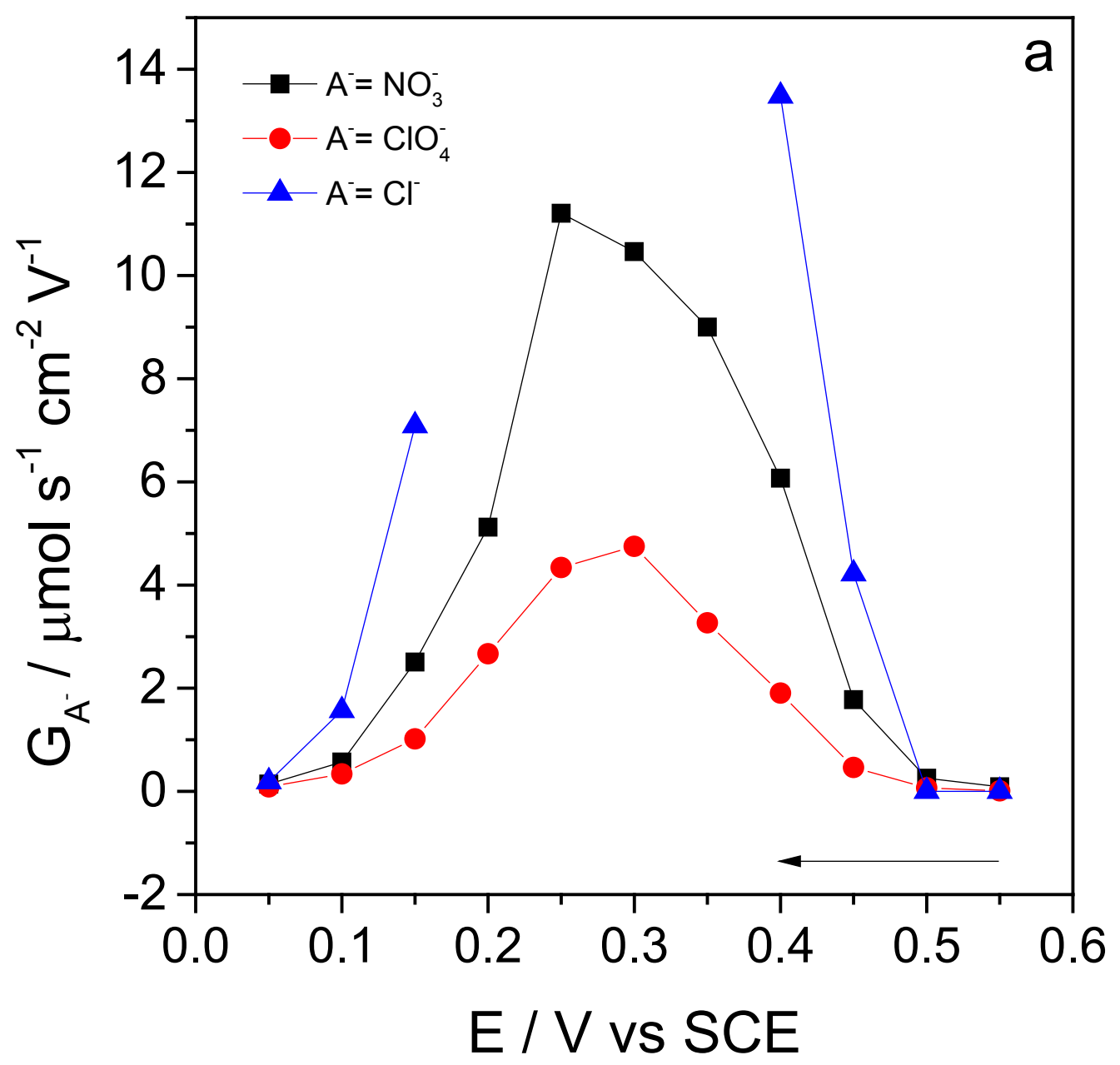

Figure 5a 
July 17, 2014

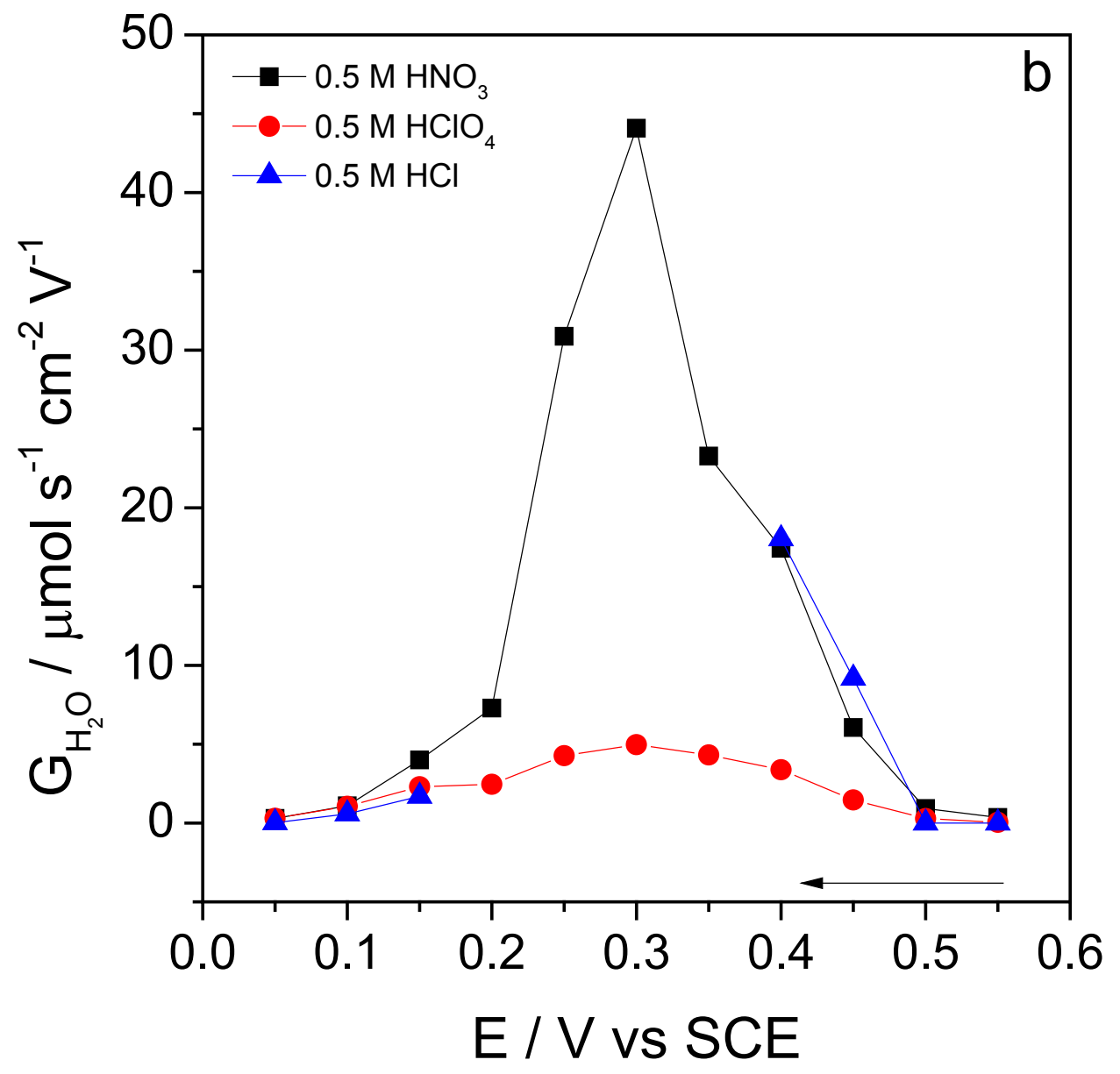

Figure $5 b$ 


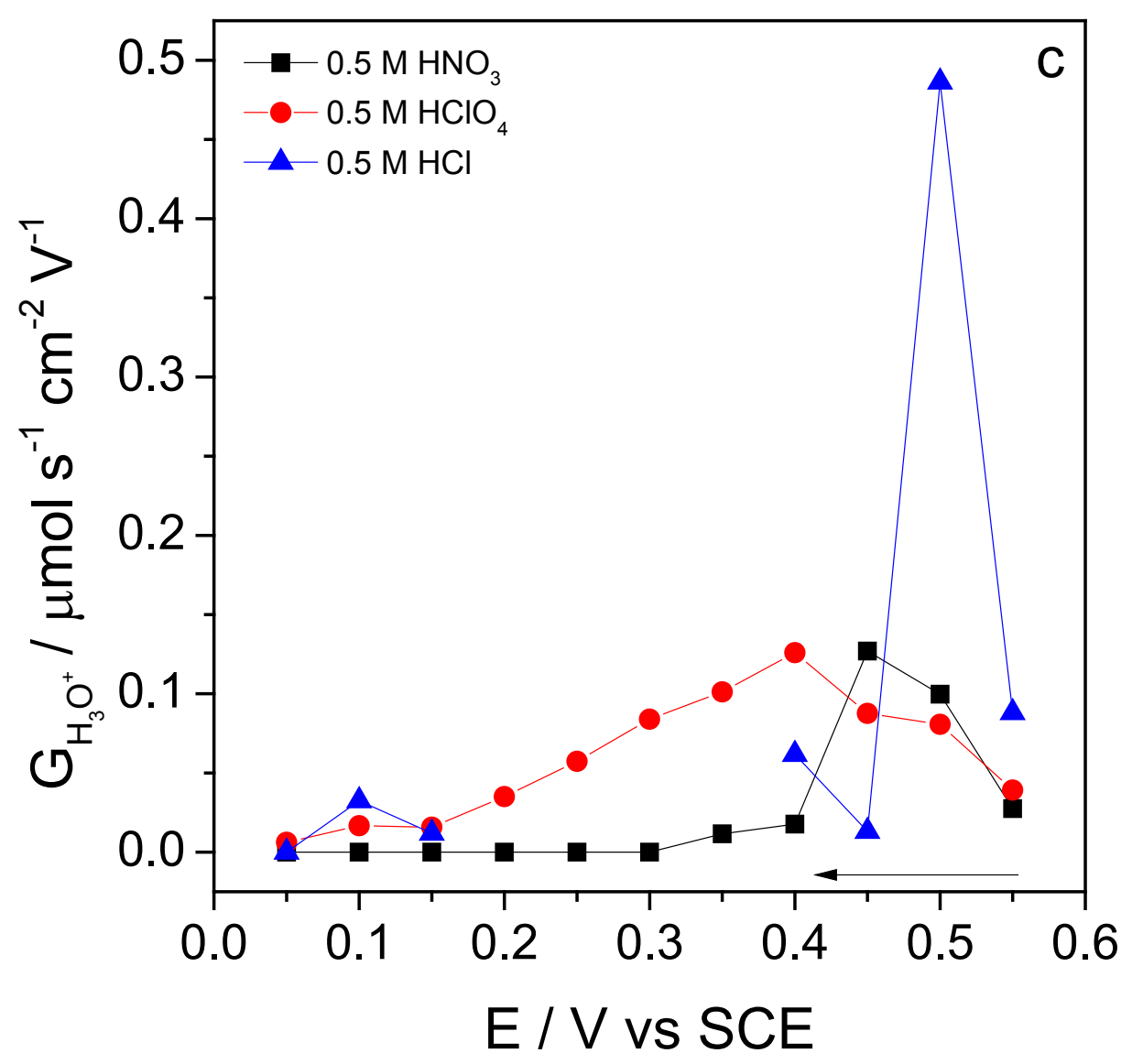

Figure 5c 
July 17, 2014

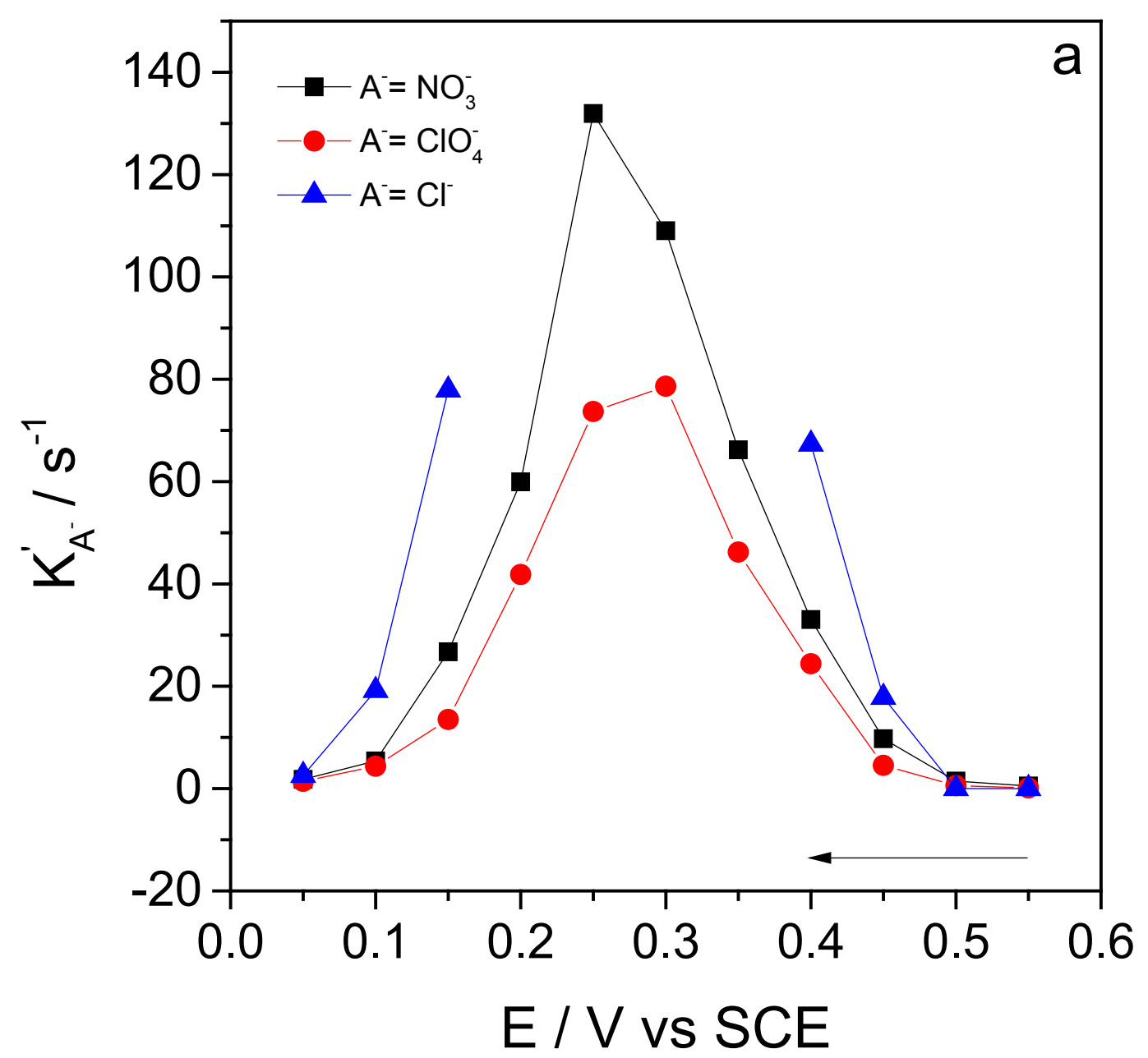

Figure 6a 


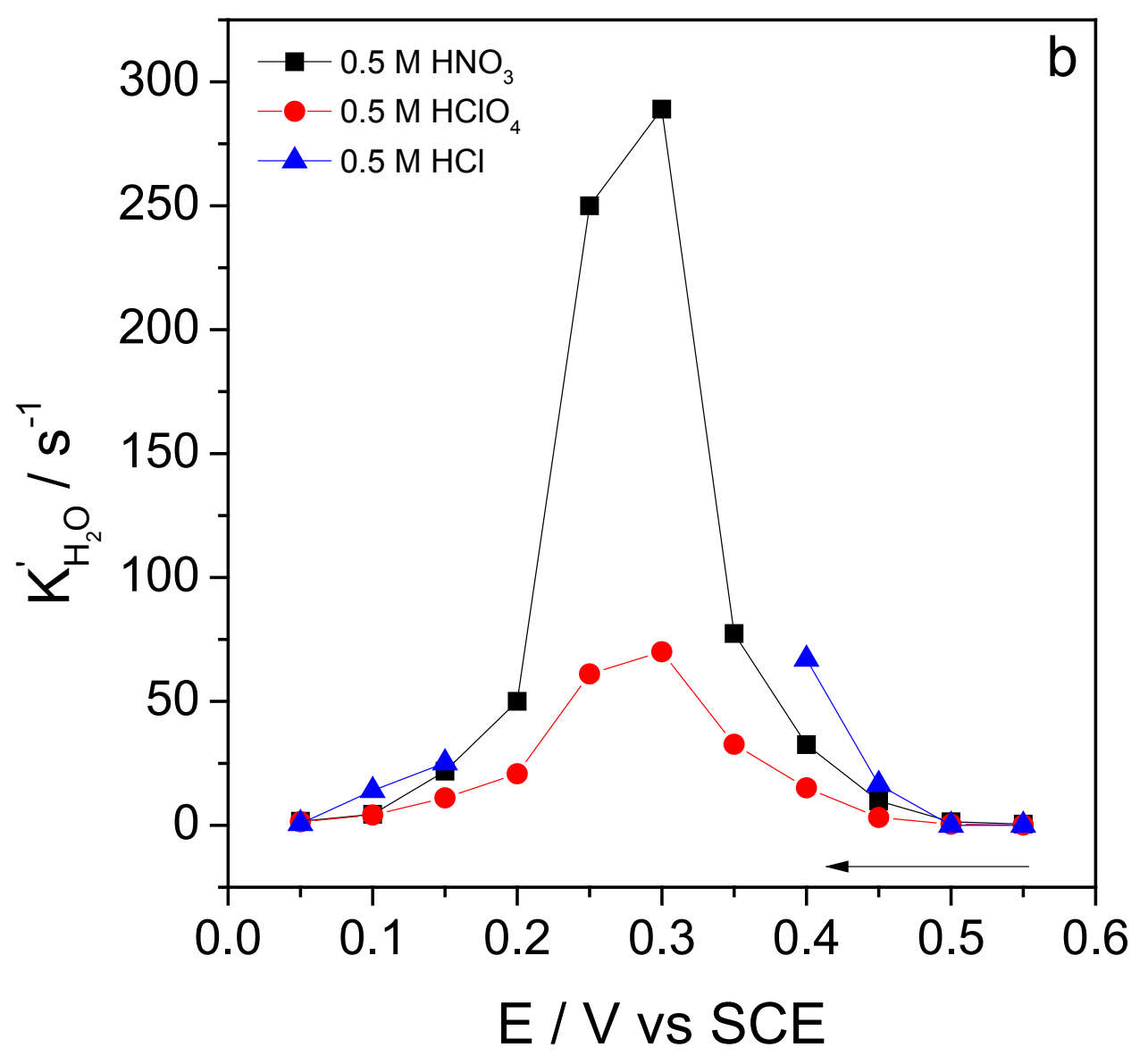

Figure $6 b$ 
July 17, 2014

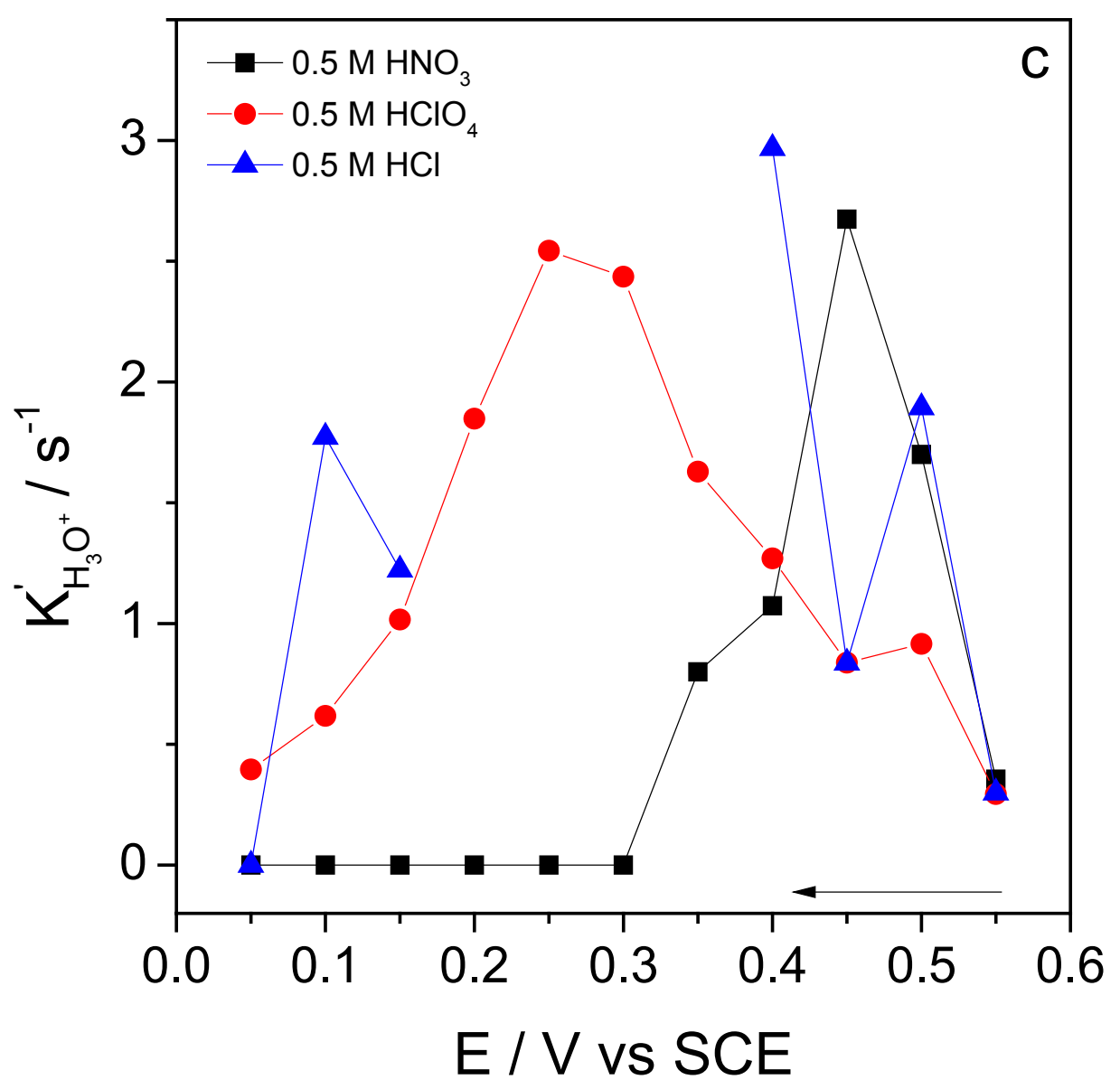

Figure $6 \mathrm{c}$ 


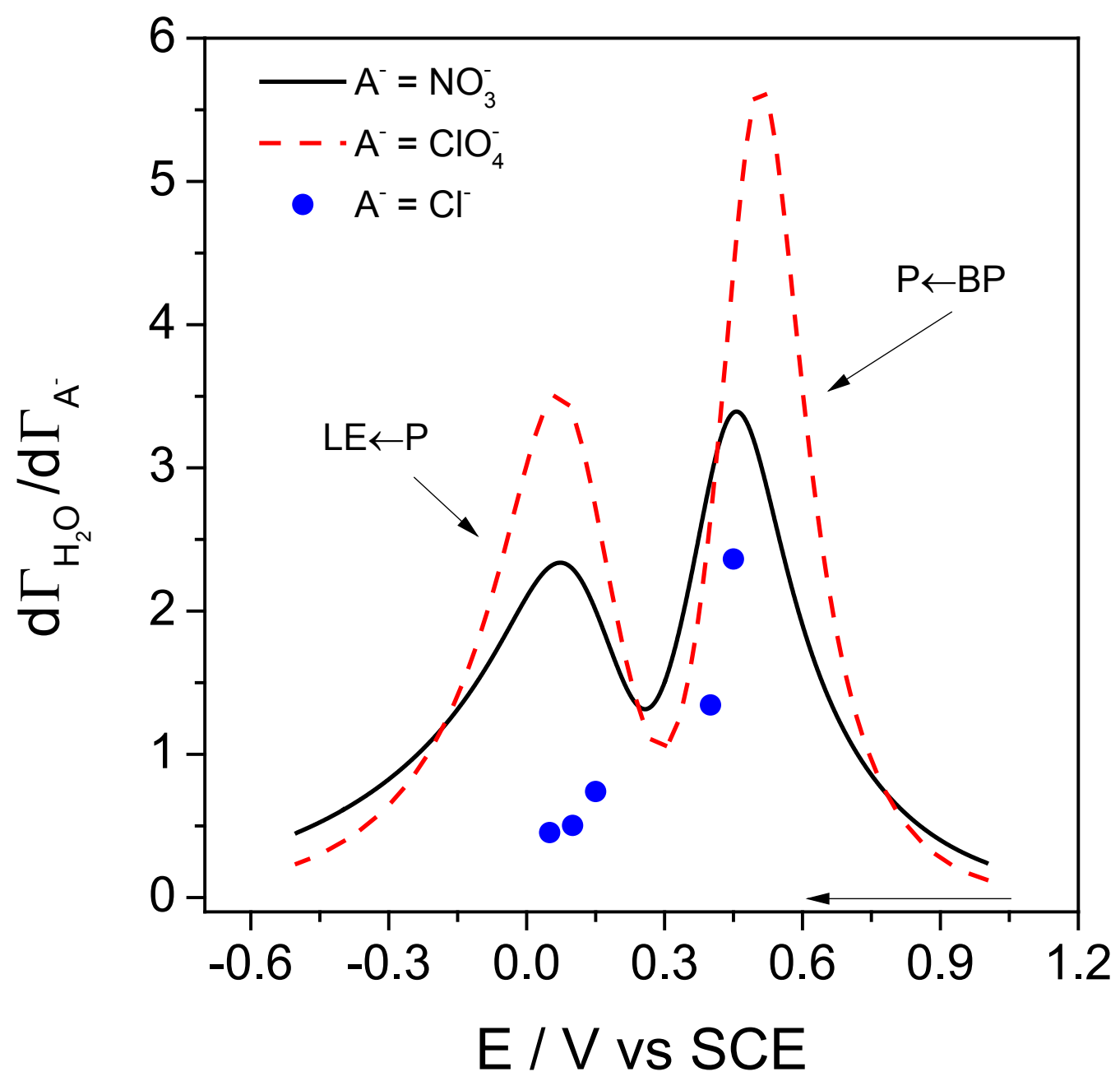

Figure 7 


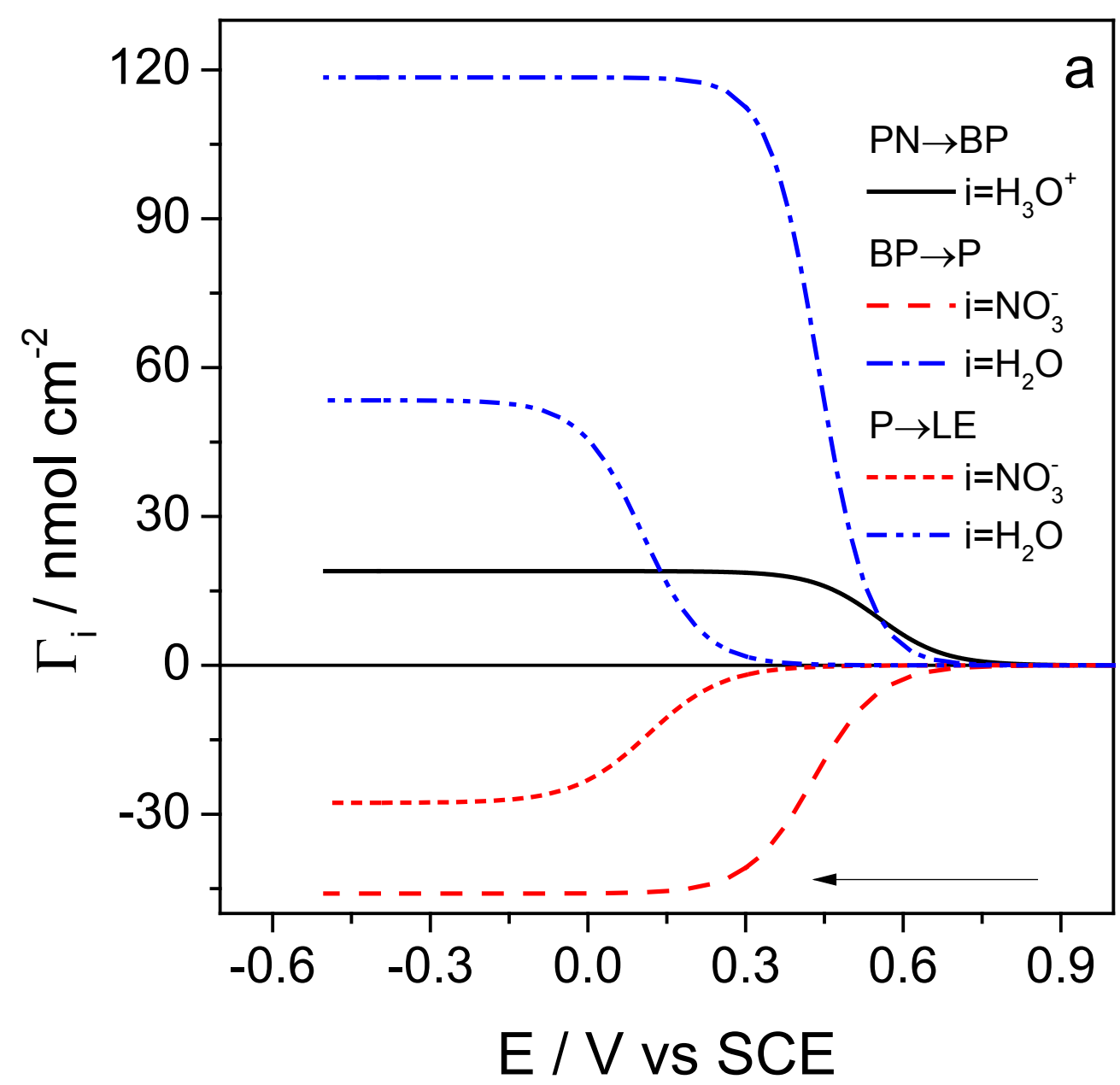

Figure $8 \mathrm{a}$ 


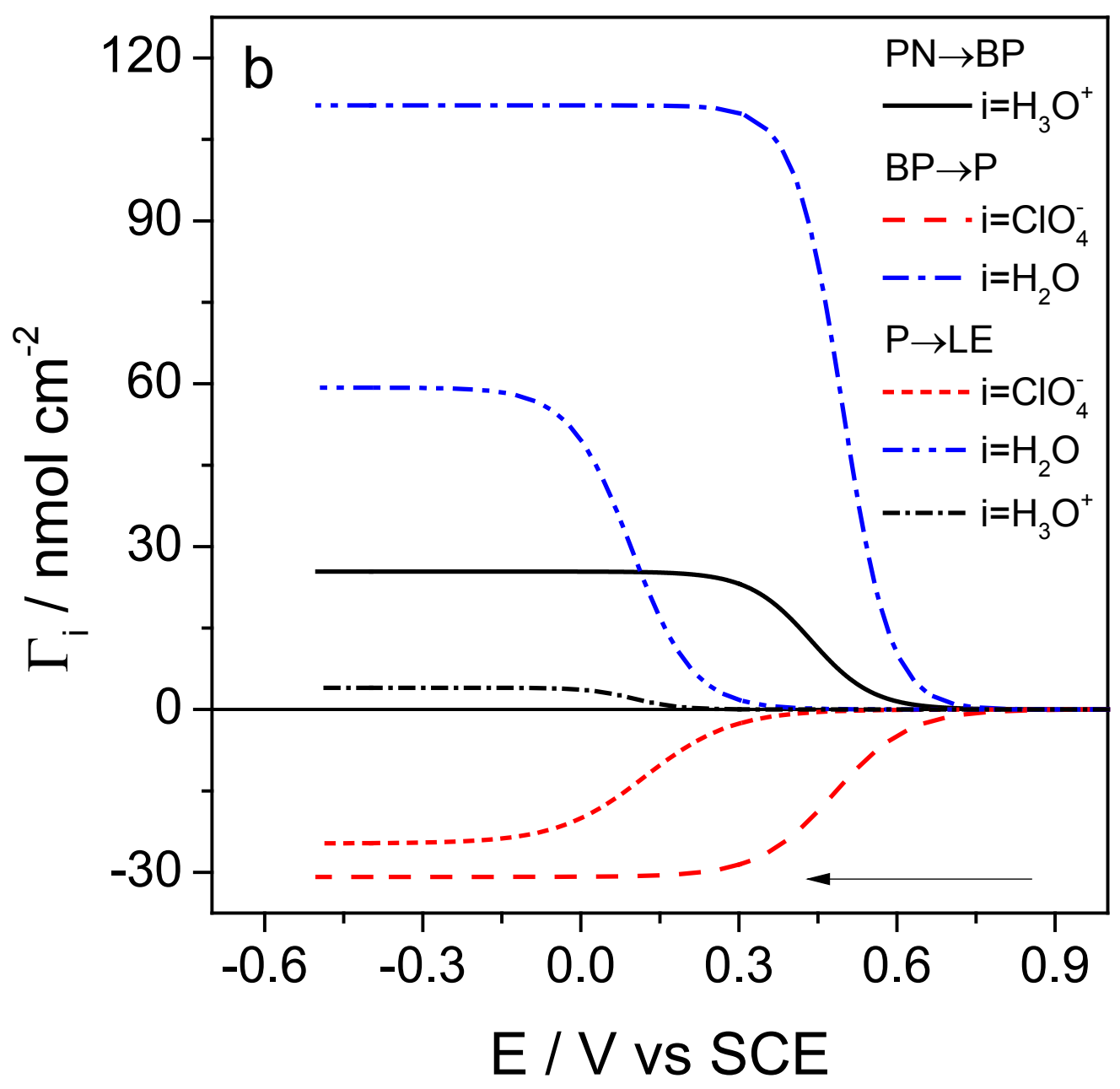

Figure $8 b$ 
July 17, 2014

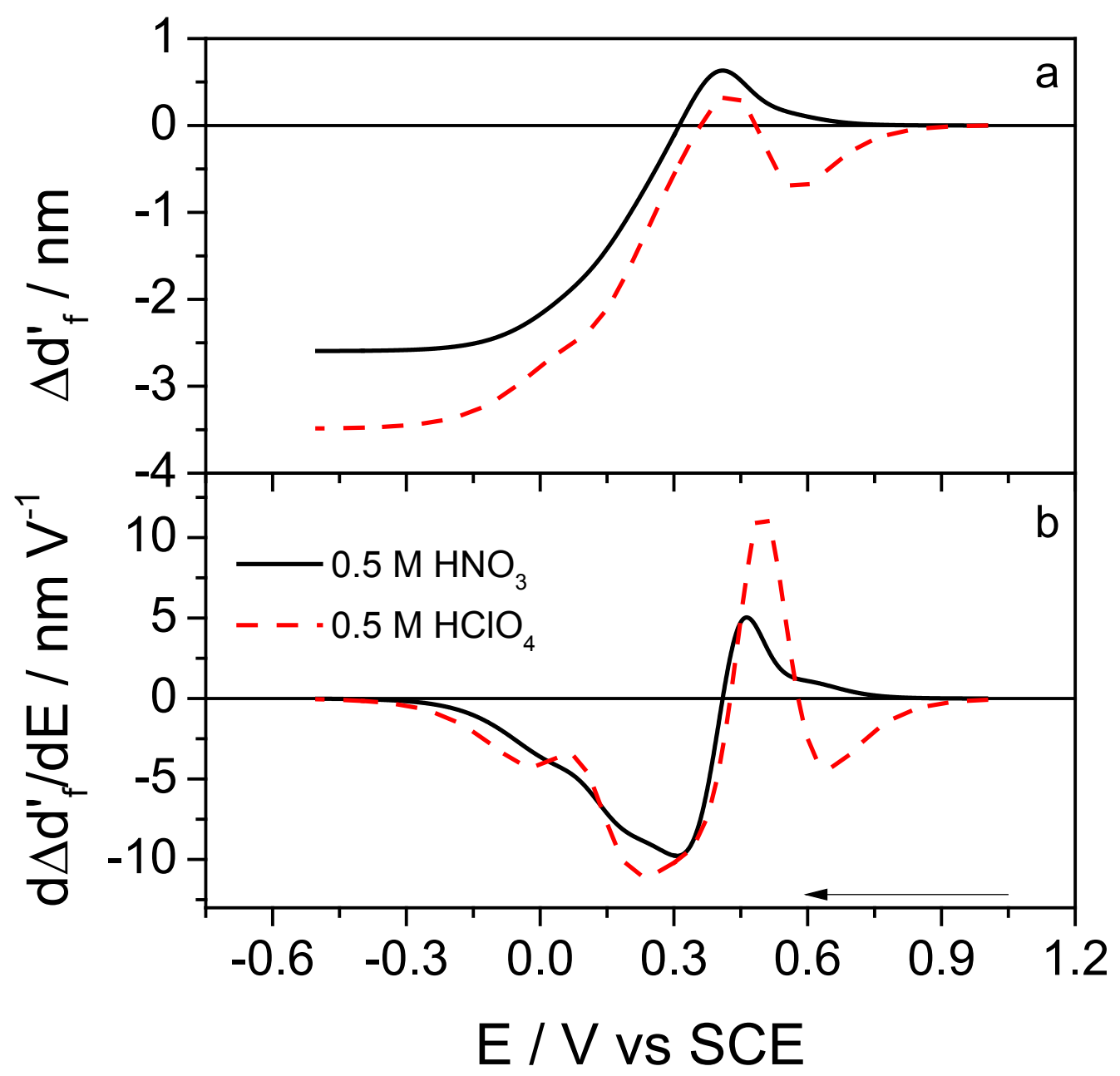

Figure 9 